\title{
Test Problems for Reactive Flow HE Model in the ALE3D Code and Limited Sensitivity Study
}

\author{
M. Gerassimenko
}

March 1, 2000

U.S. Department of Energy

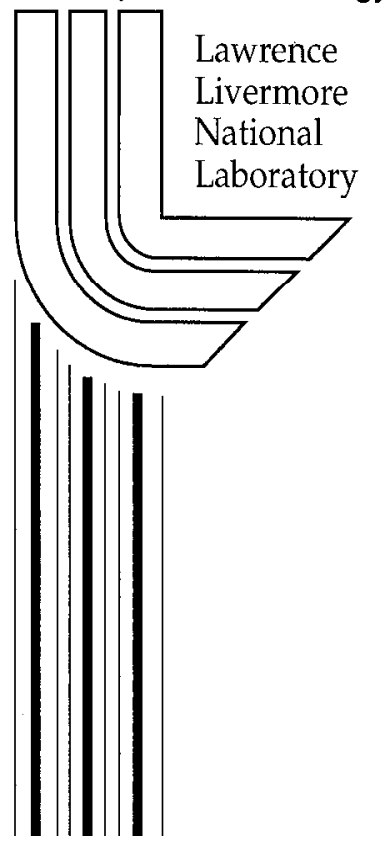




\section{DISCLAIMER}

This document was prepared as an account of work sponsored by an agency of the United States Government. Neither the United States Government nor the University of California nor any of their employees, makes any warranty, express or implied, or assumes any legal liability or responsibility for the accuracy, completeness, or usefulness of any information, apparatus, product, or process disclosed, or represents that its use would not infringe privately owned rights. Reference herein to any specific commercial product, process, or service by trade name, trademark, manufacturer, or otherwise, does not necessarily constitute or imply its endorsement, recommendation, or favoring by the United States Government or the University of California. The views and opinions of authors expressed herein do not necessarily state or reflect those of the United States Government or the University of California, and shall not be used for advertising or product endorsement purposes.

Work performed under the auspices of the U. S. Department of Energy by the University of California Lawrence Livermore National Laboratory under Contract W-7405-Eng-48.

This report has been reproduced

directly from the best available copy.

Available to DOE and DOE contractors from the

Office of Scientific and Technical Information

P.O. Box 62, Oak Ridge, TN 37831

Prices available from (423) 576-8401

http://apollo.osti.gov/bridge/

Available to the public from the

National Technical Information Service

U.S. Department of Commerce

5285 Port Royal Rd.,

Springfield, VA 22161

http://www.ntis.gov/

OR

Lawrence Livermore National Laboratory

Technical Information Department's Digital Library

http://www.llnl.gov/tid/Library.html 
UCRL-ID-

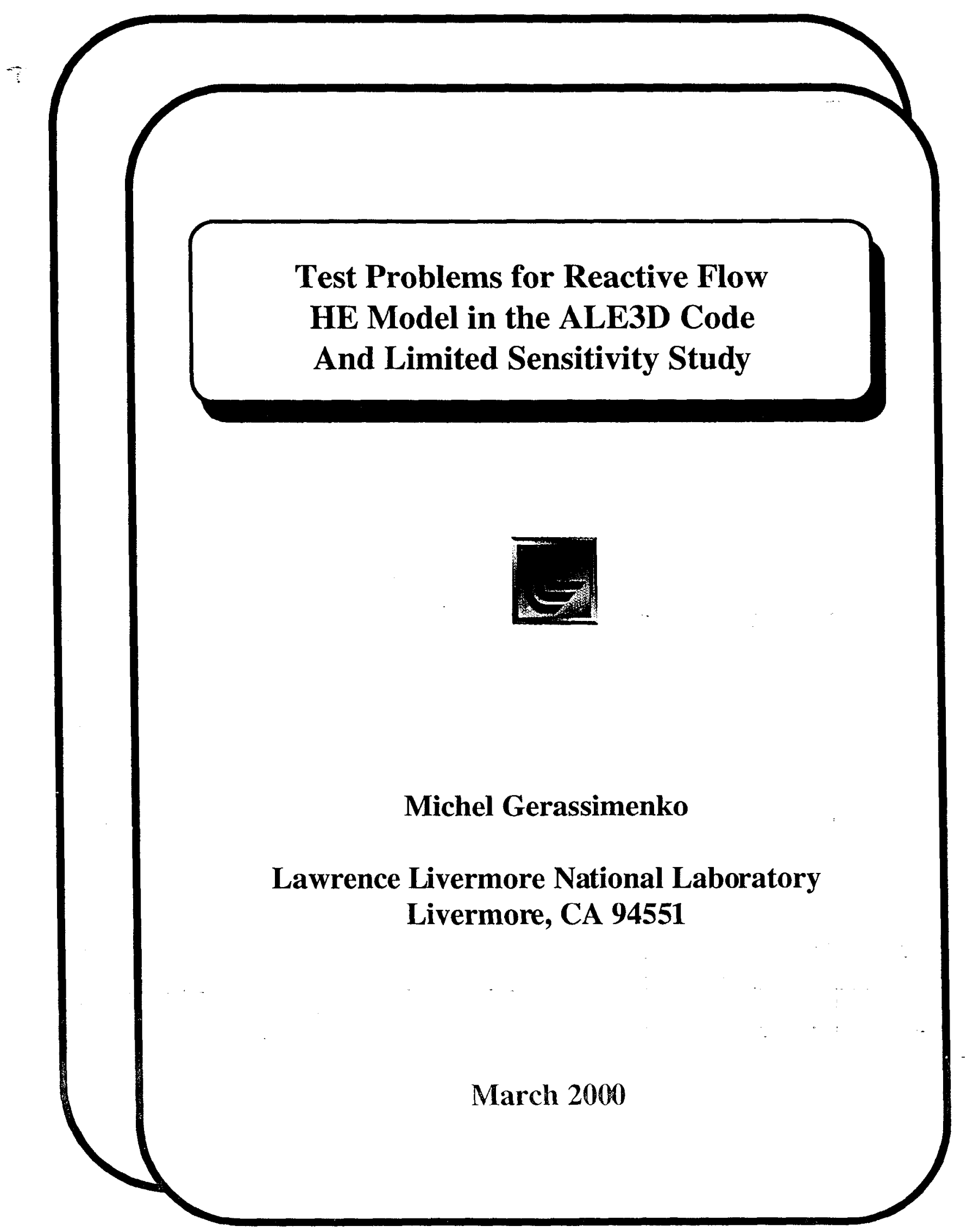


Abstract

We document quick running test problems for a reactive flow model of $\mathrm{HE}$ initiation incorporated into ALE3D. A quarter percent change in projectile velocity changes the outcome from detonation to $\mathrm{HE}$ burn that dies down. We study the sensitivity of calculated HE behavior to several parameters of practical interest where modeling HE initiation with ALE3D. 


\section{Introduction}

ALE3D is a 3D Arbitrary Lagrange Eulerian (ALE) finite element code that treats fluid and elastic plastic response of materials on an unstructured grid. A phenomenological model of $\mathrm{HE}$ initiation called the Ignition and Growth Model (IGM) which uses reactive flow has been developed at LLNL ${ }^{1,2}$ and is incorporated in the code ${ }^{3}$. In this report we document quick running test problcms that use the IGM. Running these problems ensures that new releases of the code produce results consistent with past versions. We also examine the dependence of results of these test problems on several parameters of practical intercst when modeling initiation of HE with the IGM.

\section{Test Problem Model}

The test problems model experiments which have been performed at the Naval Research Laboratory, to provide data on HE behavior near detonation threshold in axisymmetric geometry. The experiments were originally modeled with the CALE code, and experimental results have been used to refine the IGM model parameters for Comp-B which was used in the experiments. The test series consisted of balls of different materials shot at normal incidence onto round pills of Comp-B. The Comp-B is cased with tantalum in the direction facing the projectile, steel on the backside and aluminum on the outside. Projectiles are spheres of tungsten or Lexan. We choose to model experiments which produce the lowest pressure in the HE: impacts of $76 \mathrm{~mm}$ diameter Lexan spheres. An initial velocity of $1.38 \mathrm{~km} / \mathrm{sec}$ produced a delayed explosion, one at $1.44 \mathrm{~km} / \mathrm{sec}$ a detonation. Because of the symmetry of the problem, the model is set up as only one quarter of the test geometry. Reflecting boundaries are used in the two planes of symmetry, all other boundaries are open. In the original modeling of the experiments with the CALE code the initial problem setup was devoid of mixed zones, and the HE stayed that way through most of the calculation. We set up the mesh so that boundaries of the IIE and surrounding materials are coincident with zonal boundaries. This allows the HE and surrounding materials to be initially made up of clean zones. Inhibition of advection in the HE during the run can keep it frce of mixcd zones as desired. Zoning is relatively coarse in the directions normal to the projectile velocity: $\sim 8 \mathrm{~mm}$ on average, but this is reasonable in view of the large projectile dimension. In the direction of the projectile velocity, we start 
with $4 \mathrm{~mm}$ zoning in the projectile, $2 \mathrm{~mm}$ zoning in the $\mathrm{HE}$ and backplate and $\sim 1.2 \mathrm{~mm}$ zoning in the thin tantalum front plate. Material weights keep zoning concentrated in the front plate and the HE as the mesh is relaxed during the run. We start out by relaxing the mesh for 100 iterations. A materials map with zoning indicated is shown at that point in Figure 1.

\section{Test problem runs output}

We started out with our standard test problems documented in the appendix with an initial projectile velocity of $1.38 \mathrm{~km} / \mathrm{s}$ and $1.44 \mathrm{~km} / \mathrm{s}$ run with version 2.9 .0 of ALE3D. The evolution of the $1.38 \mathrm{~km}$ initial projectile velocity run is shown in Figures 2 through 12, which are quad views of the calculation with the two symmetry planes at the front and left. The right side of each figure shows the total zonal burned $\mathrm{HE}$ fraction (top, scale of 0: blue to 1: red) and zonal pressure (bottom, scale of 0: blue to $100 \mathrm{kbar}$ : red) in the HE. Pressure within the HE peaks between $40 \mu \mathrm{s}$ and $45 \mu \mathrm{s}$, and HE burn becomes negligible after $70 \mu \mathrm{s}$. The evolution of the $1.44 \mathrm{~km} / \mathrm{s}$ initial projectile velocity run is shown in Figures 13 through 17. Pressure builds up in the middle of the HE pill by $35 \mu$ s and a detonation soon follows. We stopped the calculation at $45 \mu$ s since the outcome is clear, while the time step which is controlled by $\mathrm{HE}$ burn is very small.

We varied the projectile velocity by $0.005 \mathrm{~km} / \mathrm{s}$ to establish the detonation threshold. The evolution of a $1.385 \mathrm{~km} / \mathrm{s}$ initial projectile velocity run is shown in Figures 18 through 28. The HE behavior is very similar to that of the $1.38 \mathrm{~km} / \mathrm{s}$ initial projectile velocity, although there is a bit more burned HE. The evolution of a $1.390 \mathrm{~km} / \mathrm{s}$ initial velocity run is shown in Figures 29 through 37 . The HE behavior is similar to that of the $1.385 \mathrm{~km} / \mathrm{s}$ initial projectile velocity run up to $40 \mu \mathrm{s}$. At 45 $\mu$ s pressure in the $\mathrm{HE}$ is higher and more $\mathrm{HE}$ has burned. HE pressure builds up until a detonation takes off at $60 \mu \mathrm{s}$ at the rear of the HE pill. The initial projectile velocity differs by only 0.36 percent. The result is radically different $\mathrm{HE}$ behavior. These two runs are a sensitive test of the model performance in the code.

\section{Limited sensitivity study}

We are interested in the dependence of the HE response calculated with the IGM model to some parameters which are often altered in calculations, and initial setup conditions. 


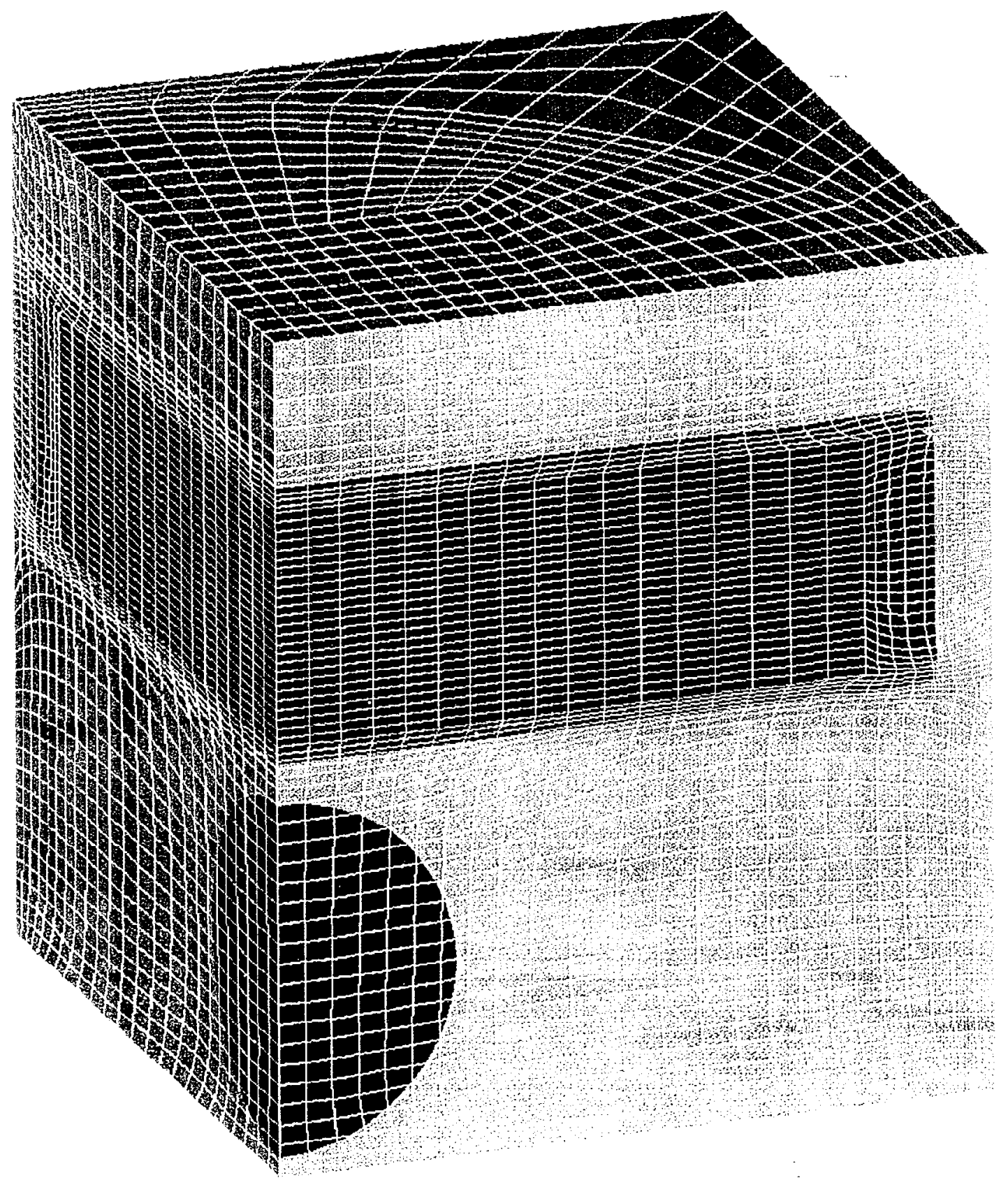

Figure 1: $\quad$ Materials map at start of problem with zoning indicated. The front and left faces are symmetry planes. Red = Lexan projectile, green $=$ tantalum cover, dark blue $=\mathrm{HE}$, purple $=$ steel back plate, light blue $=$ aluminum outer ring, yellow $=$ air. 

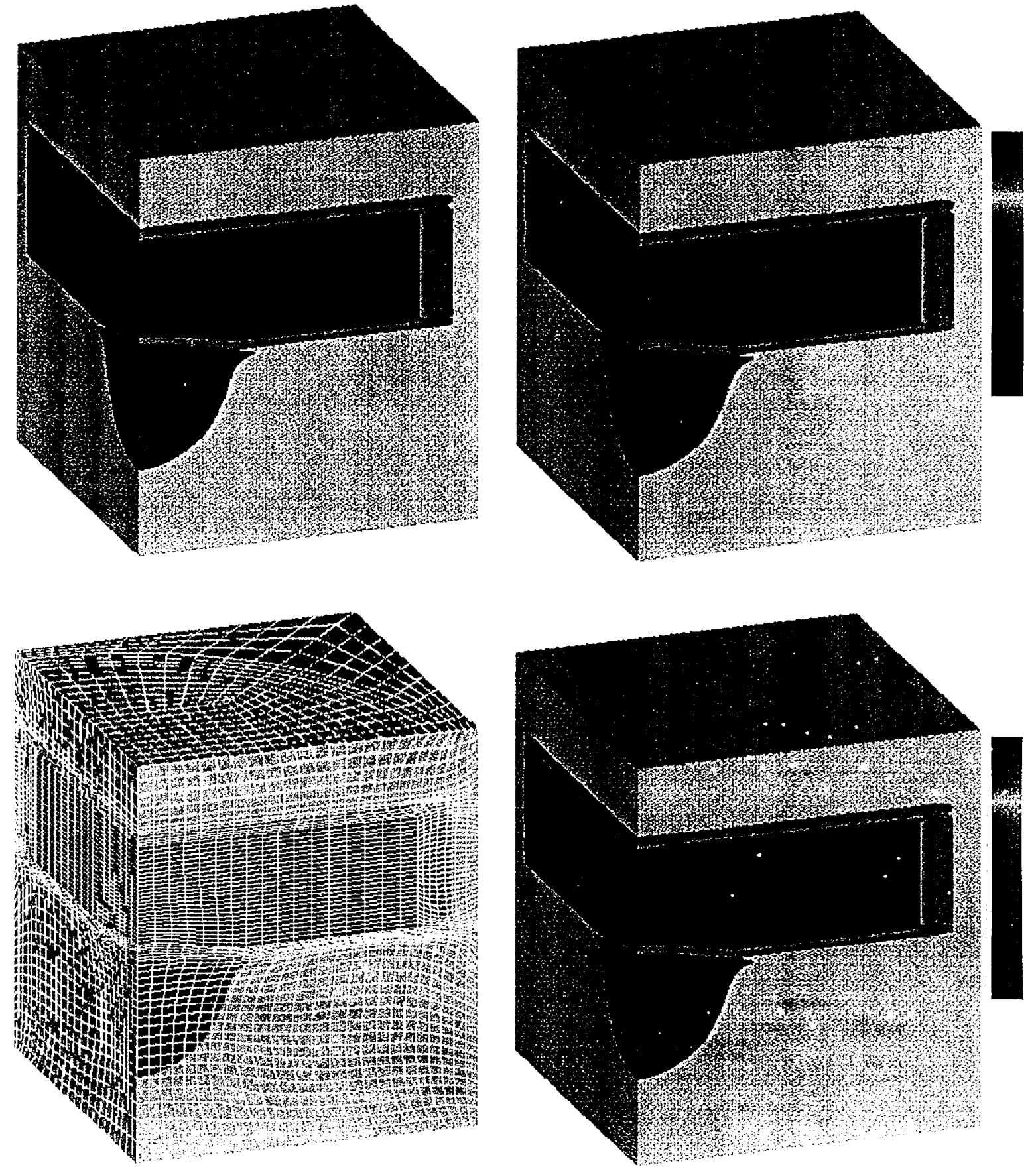

Figure 2: Initial projectile velocity $1.38 \mathrm{~km} / \mathrm{s}$ at $25 \mu \bar{s}$. Materials maps with zoning (bottom left), reacted HE fraction (top right, scale of 0 to 1) and $\mathrm{HE}$ pressure (bottom right, scale of 0 to 100 kbar). 

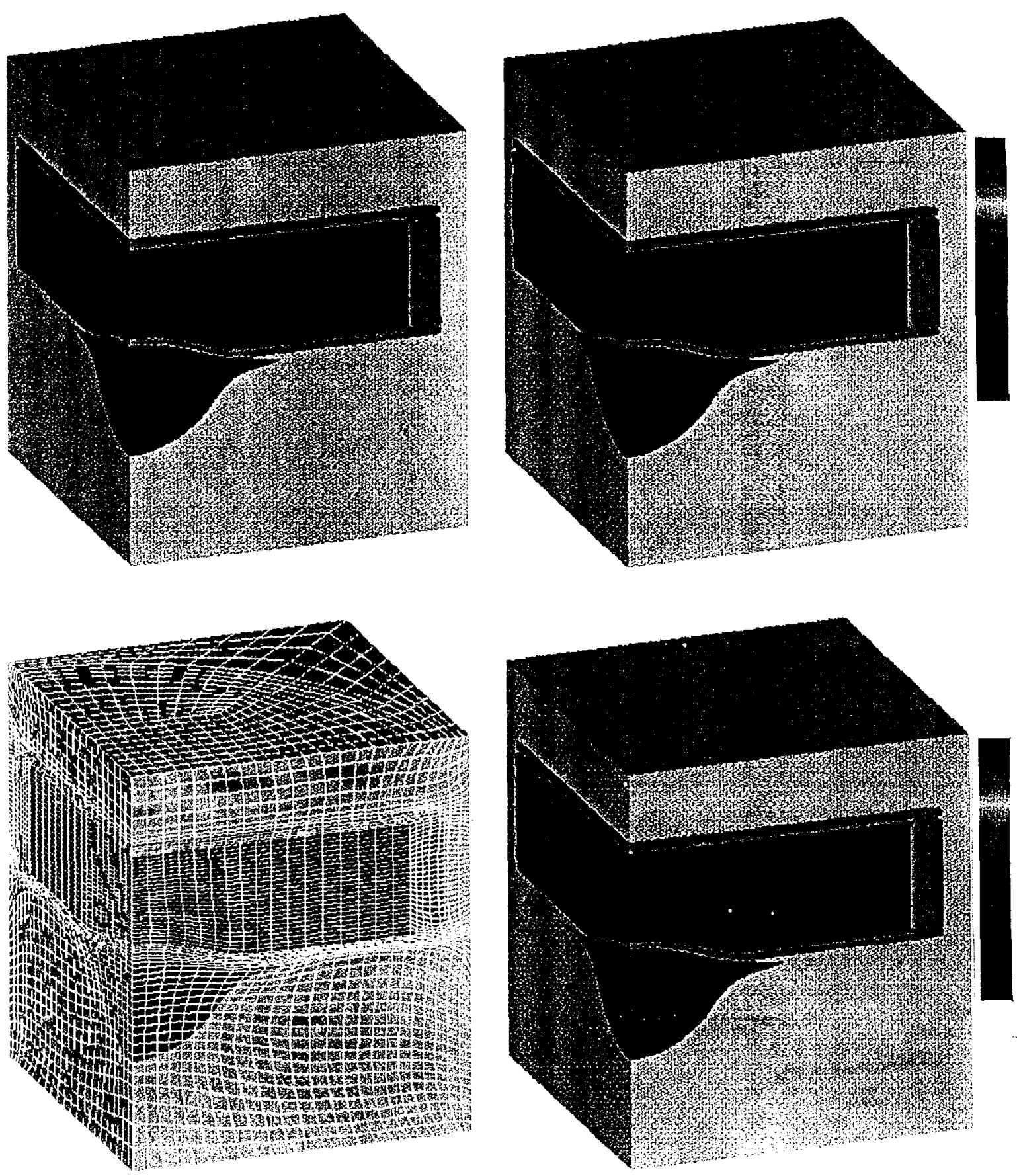

Figure 4: Initial projectile velocity $1.38 \mathrm{~km} / \mathrm{s}$ at $35 \mu \mathrm{s}$. Materials maps with zoning (bottom left), reactcd HE fraction (top right, scale of 0 to 1 ) and $\mathrm{HE}$ pressure (bottom right, scale of 0 to 100 kbar). 

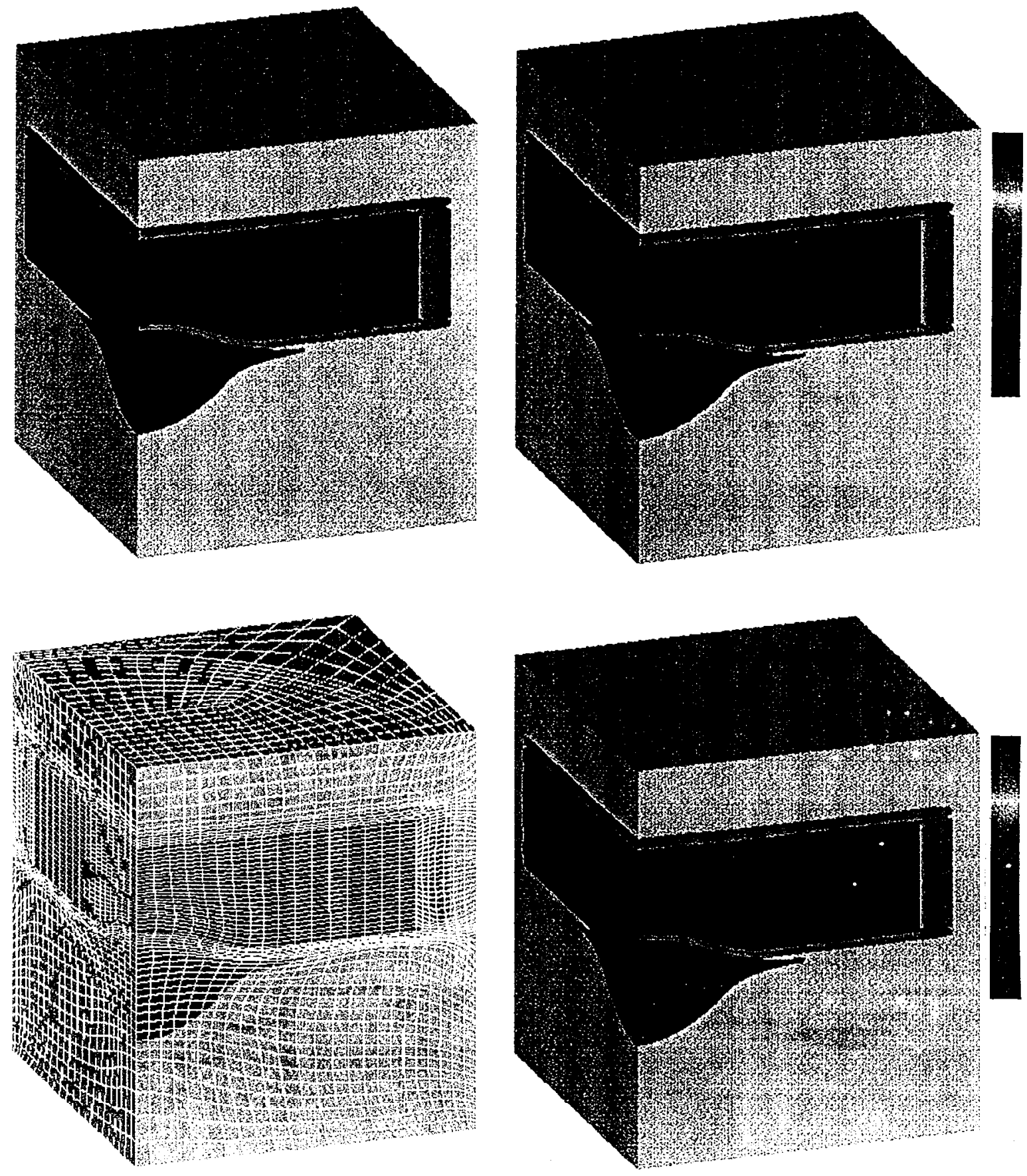

Figure 5: Initial projectile velocity $1.38 \mathrm{~km} / \mathrm{s}$ at $40 \mu \mathrm{s}$. Materials mäps with zoning (bottom left), reacted HE fraction (top right, scale of 0 to 1) and HE pressure (bottom right, scale of 0 to 100 kbar). 

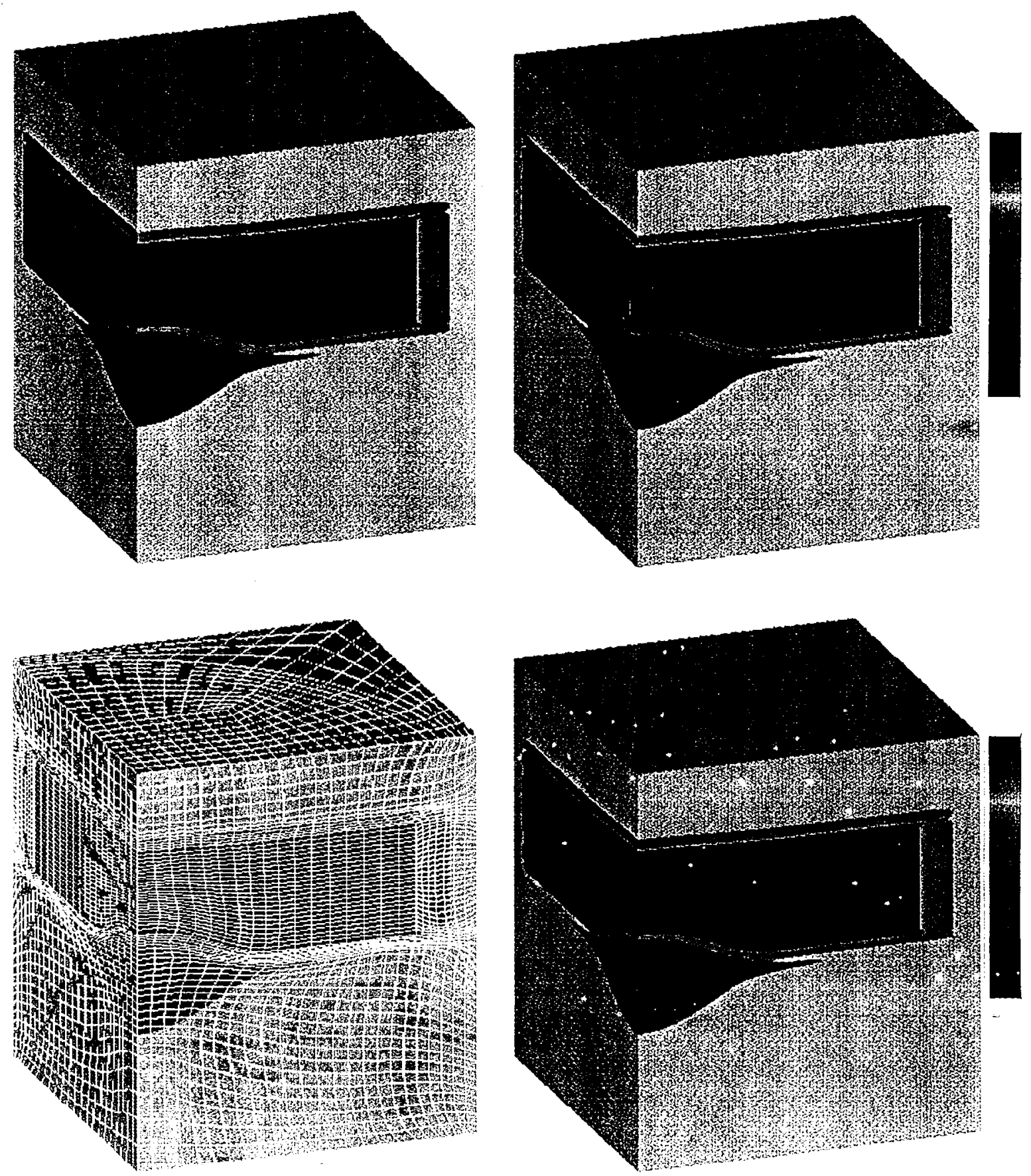

Figure 6: Initial projectile velocity $1.38 \mathrm{~km} / \mathrm{s}$ at $45 \mu \mathrm{s}$. Materials maps with zoning (bottom left), reacted HE fraction (top right, scale of $\mathrm{O}$ to 1 ) and $\mathrm{HE}$ pressure (bottom right, scale of 0 to 100 kbar). 

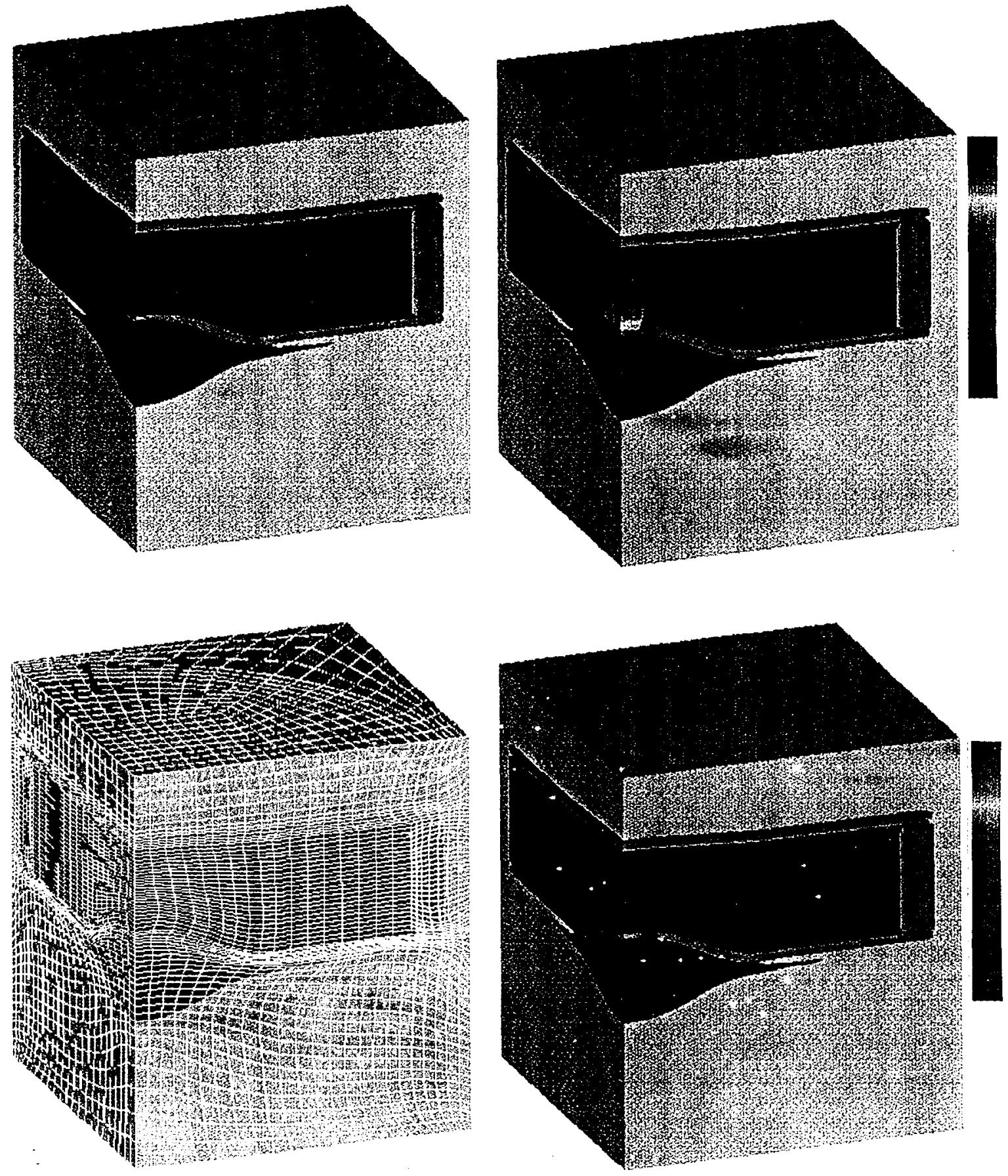

Figure 7: Initial projectile velocity $1.38 \mathrm{~km} / \mathrm{s}$ at $50 \mu \mathrm{s}$. Materials maps with zoning (bottom left), reacted HE fraction (top right, scale of 0 to 1 ) and ILE pressure (bottom right, scale of 0 to 100 kbar). 

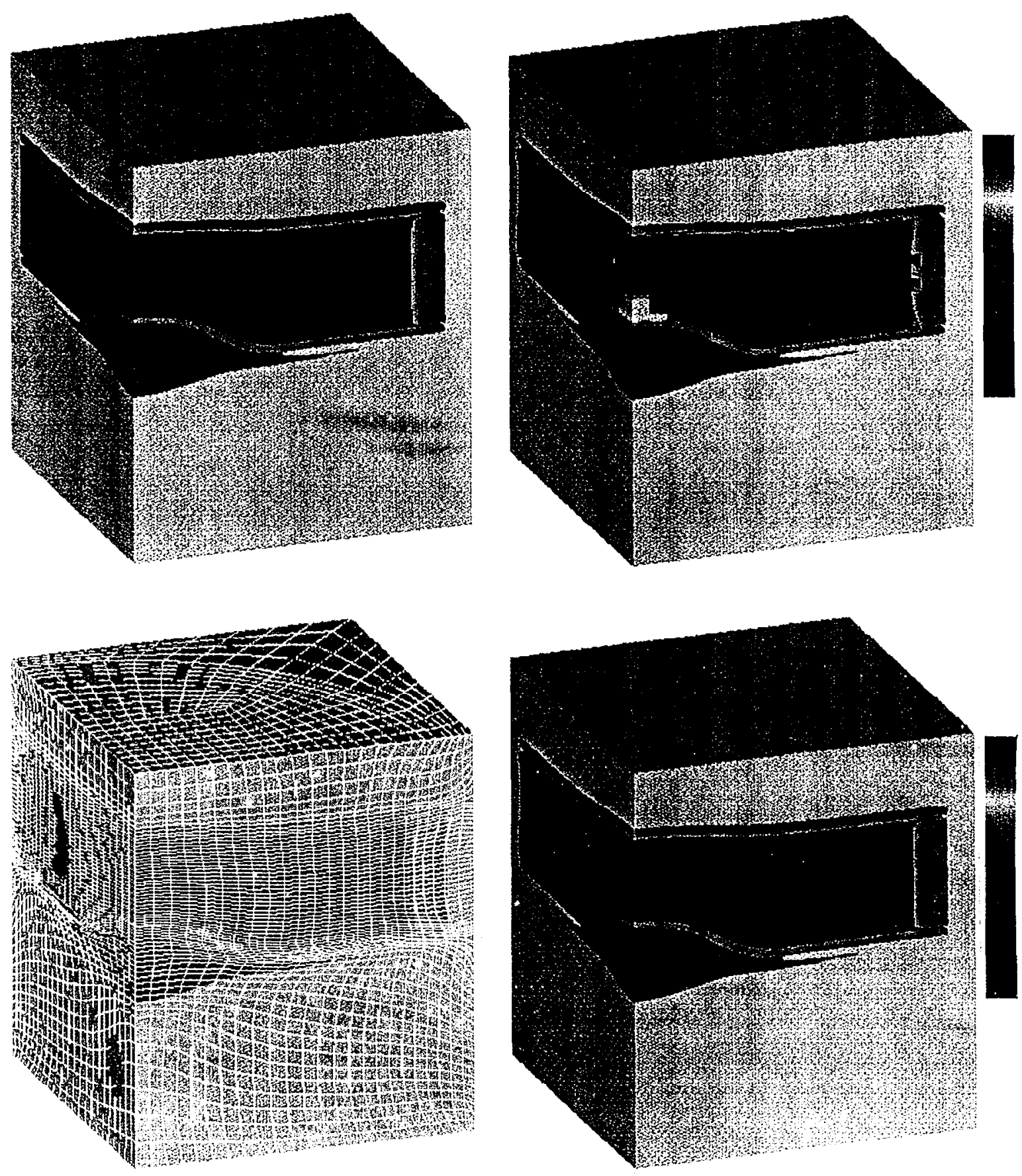

Figure 8: Initial projectile velocity $1.38 \mathrm{~km} / \mathrm{s}$ at $60 \mu \mathrm{s}$. Materials mäps with zoning (bottom left), reacted $\mathrm{HE}$ fraction (top right, scale of $O$ to 1) and HE pressure (bottom right, scale of $O$ to 100 kbar). 

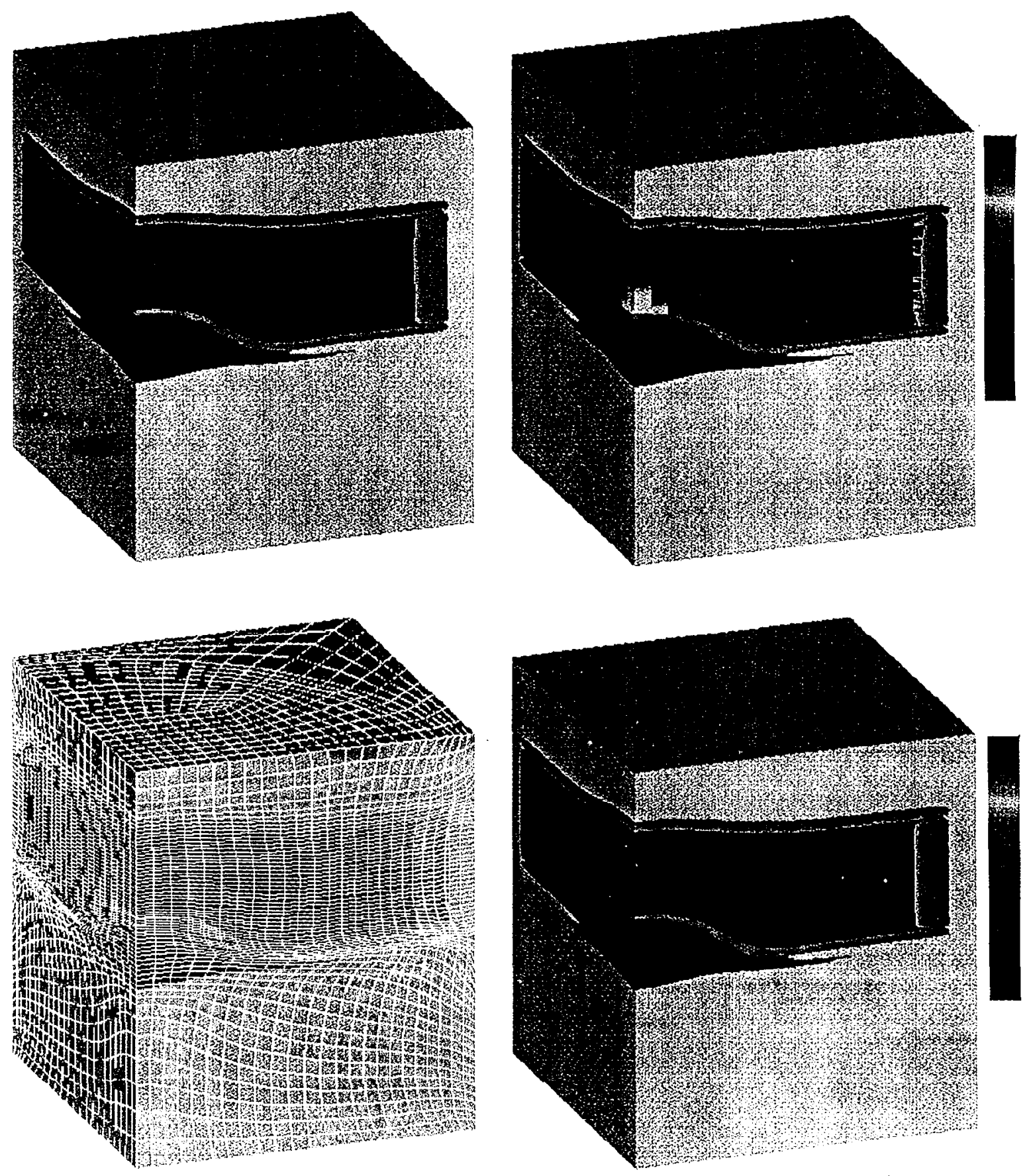

Figure 9: Initial projectile velocity $1.38 \mathrm{~km} / \mathrm{s}$ at $70 \mu \mathrm{s}$. Materials maps with zoning (bottom left), reacted $\mathrm{HE}$ fraction (top right, scale of $\mathrm{O}$ to 1 ) and $\mathrm{HE}$ pressure (bottom right, scale of $\mathrm{O}$ to 100 kbar). 

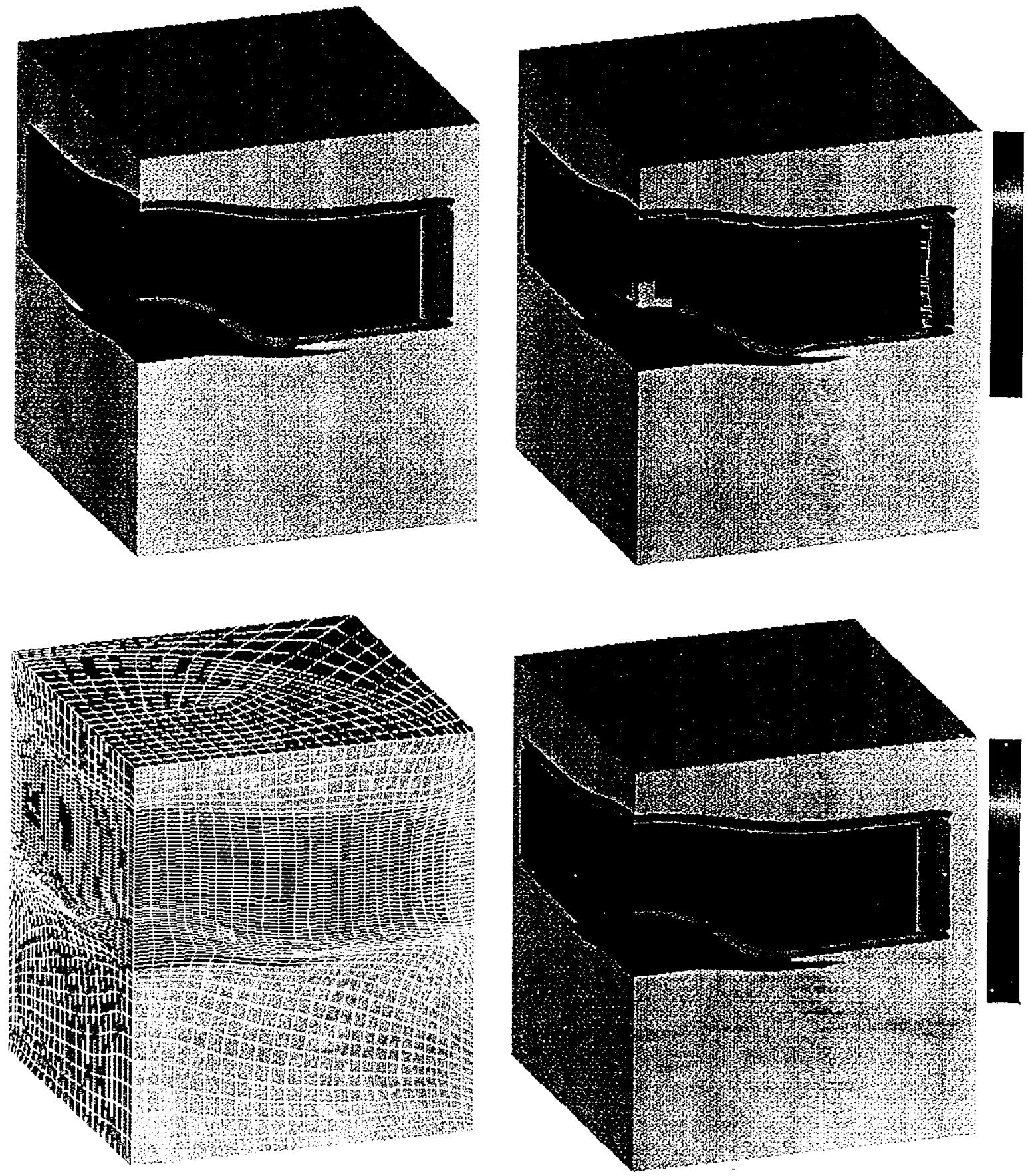

Figure 10: Initial projectile velocity $1.38 \mathrm{~km} / \mathrm{s}$ at $80 \mu \mathrm{s}$. Materials maps with zoning (bottom left), reacted $\mathrm{HE}$ fraction (top right, scale of $\mathrm{O}$ to 1 ) and $\mathrm{HE}$ pressure (bottom right, scale of 0 to 100 kbar). 

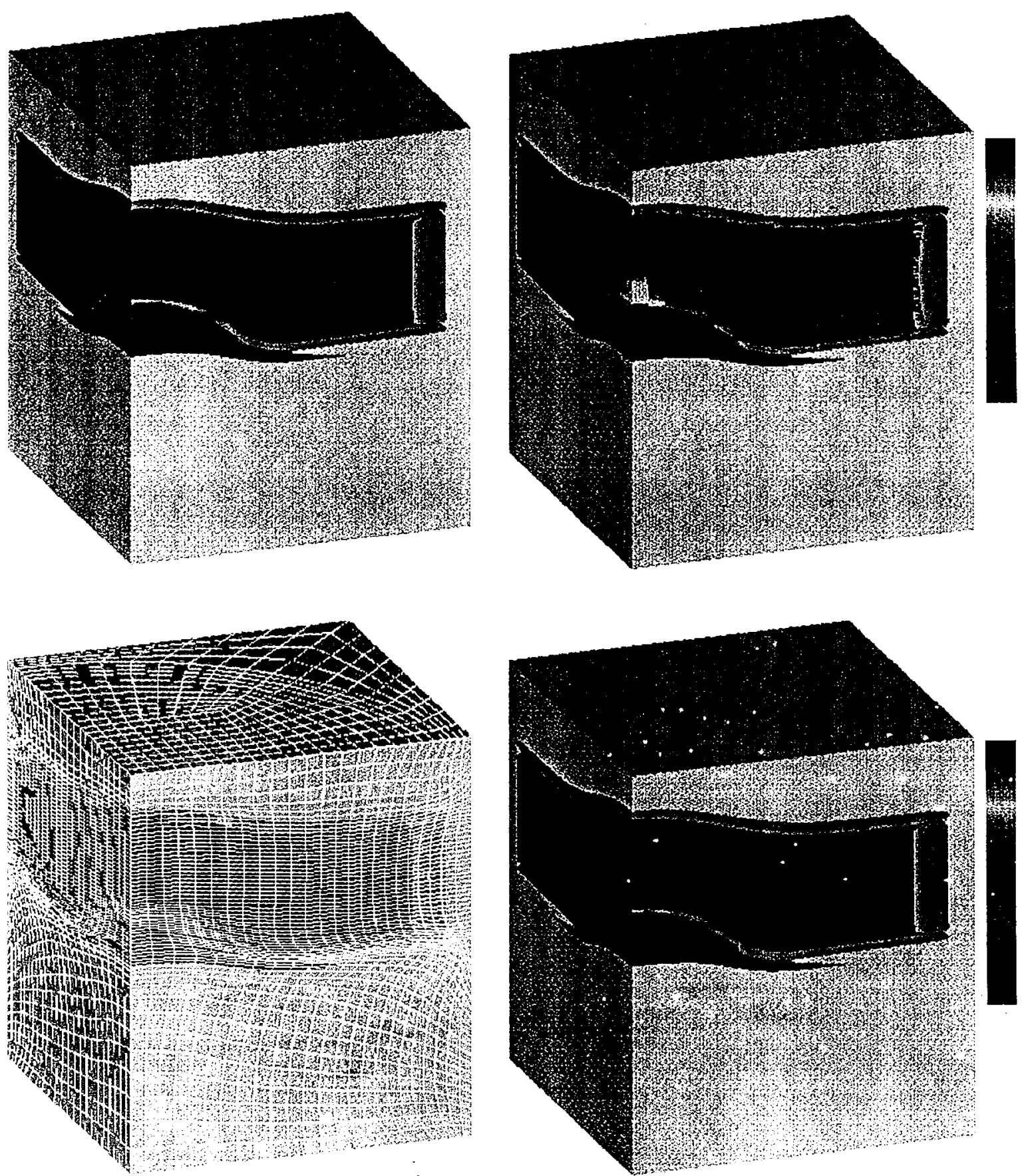

Figure 11: Initial projectile velocity $1.38 \mathrm{~km} / \mathrm{s}$ at $90 \mu \mathrm{s}$. Materials maps with zoning (bottom left), reacted HE fraction (top right, scale of 0 to 1) and HE pressure (bottom right, scale of 0 to 100 kbar). 

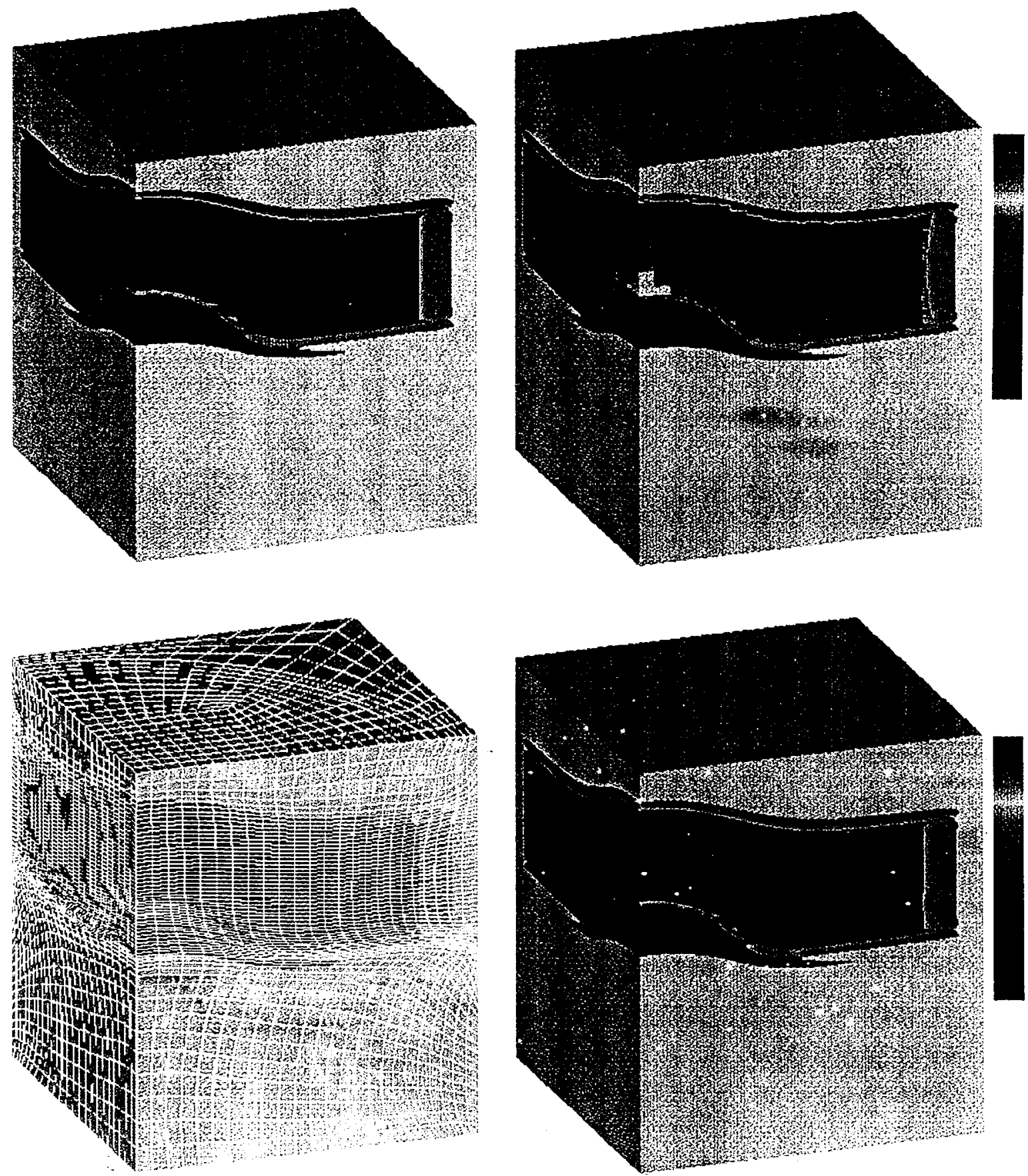

Figure 12: Initial projectile velocity $1.38 \mathrm{~km} / \mathrm{s}$ at $100 \mu \mathrm{s}$. Materials maps with zoning (bottom left), reacted HE fraction (top right, scale of $\mathrm{O}$ to 1 ) and $\mathrm{HE}$ pressure (bottom right, scale of 0 to $100 \mathrm{kbar}$. 

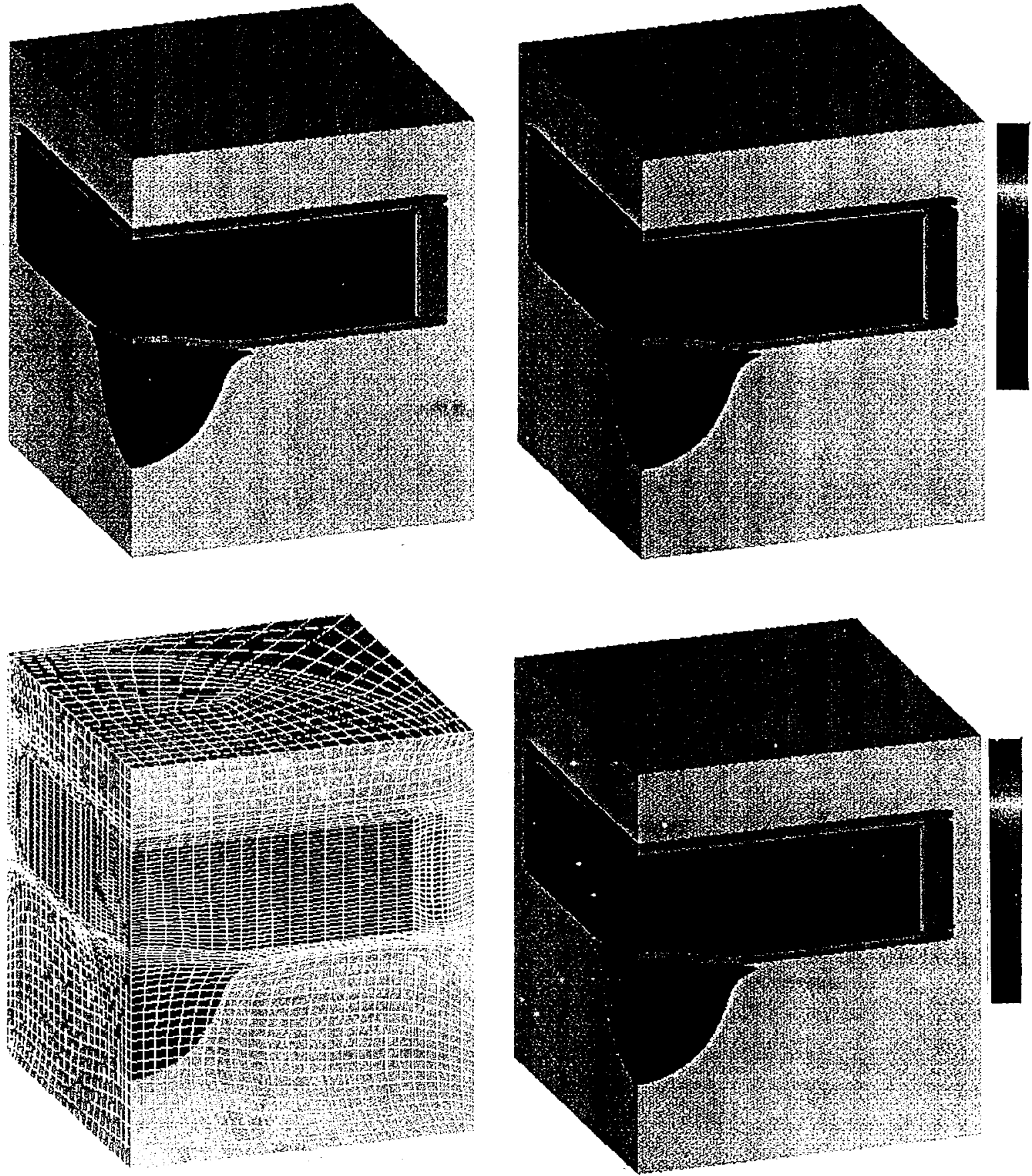

Figure 13: Initial projectile velocity $1.44 \mathrm{~km} / \mathrm{s}$ at $25 \mu \mathrm{s}$. Matcrials maps with zoning (bottom left), reacted $\mathrm{HE}$ fraction (top right, scale of 0 to 1) and $\mathrm{HE}$ pressure (bottom right, scale of 0 to 100 kbar). 



Figure 14: Initial projectile velocity $1.44 \mathrm{~km} / \mathrm{s}$ at $30 \mu \mathrm{s}$. Materials maps with zoning (bottom left), reacted HE fraction (top right, scale of 0 to 1) and HE pressure (bottom right, scale of 0 to 100 kbar). 

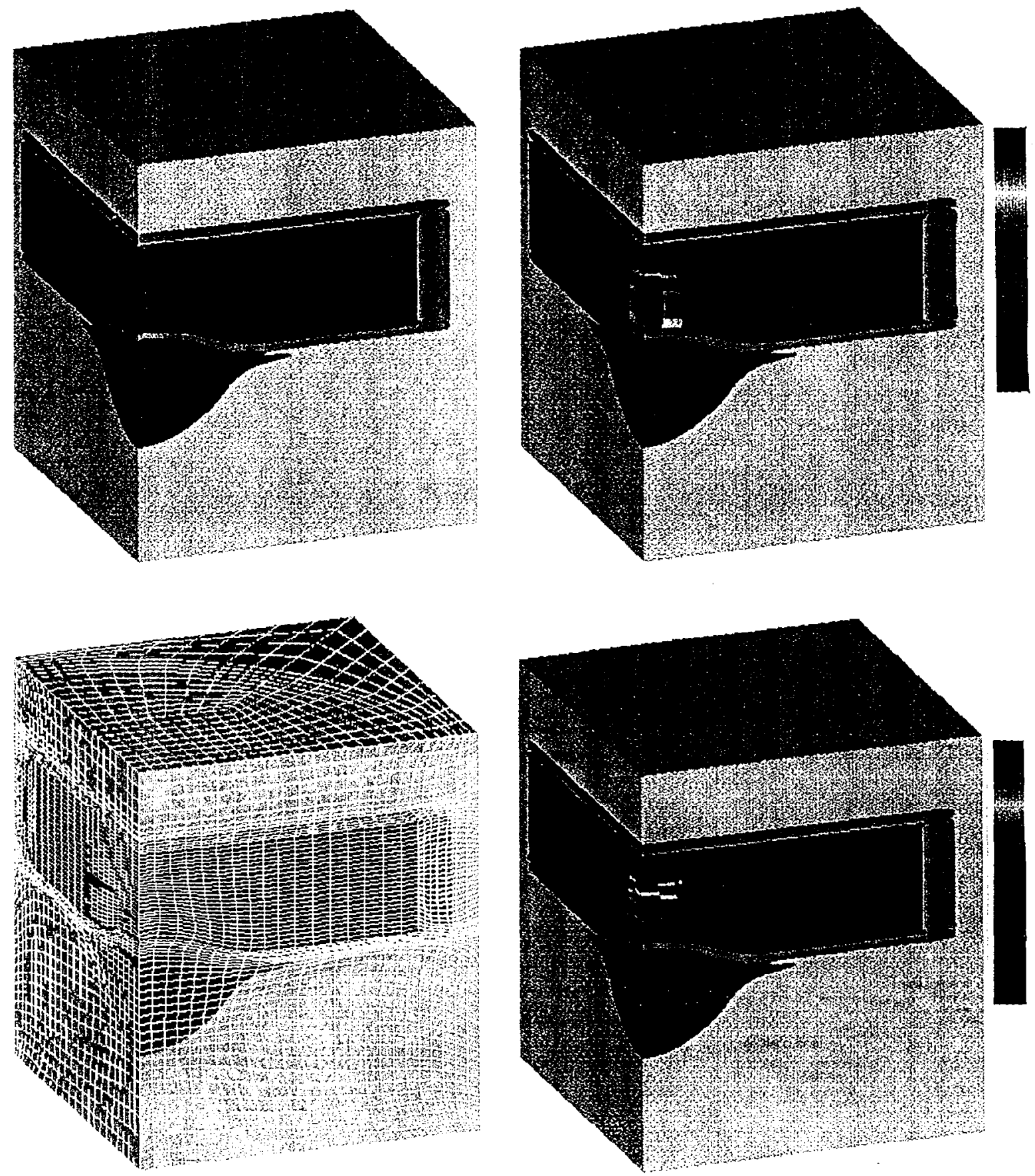

Figure 15: Initial projectile velocity $1.44 \mathrm{~km} / \mathrm{s}$ at $35 \mu \mathrm{s}$. Materials maps with zoning (bottom left), reacted $\mathrm{HE}$ fraction (top right, scale of 0 to 1) and HE pressure (bottom right, scale of 0 to 100 kbar). 

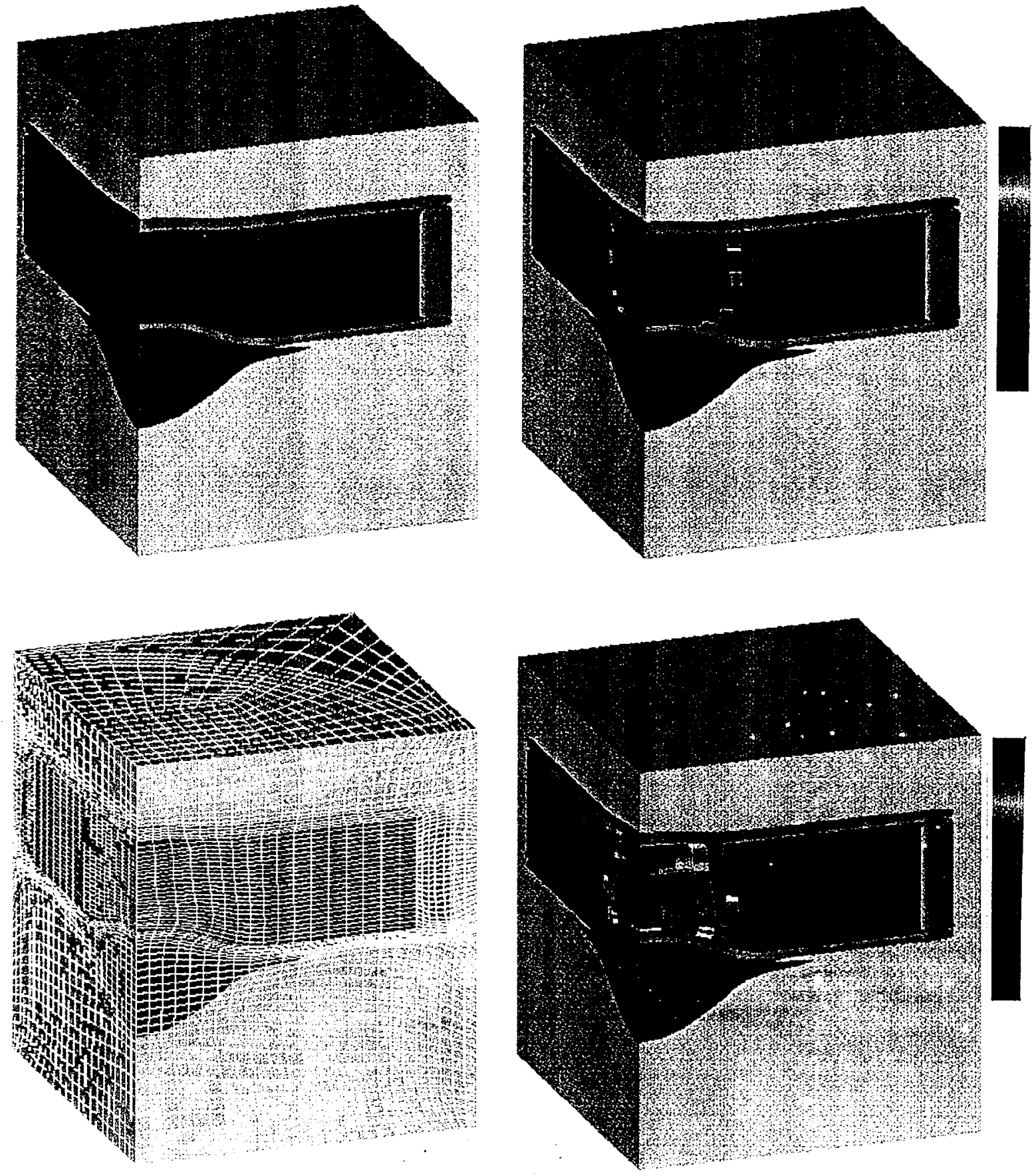

Figure 16: Initial projectile velocity $1.44 \mathrm{~km} / \mathrm{s}$ at $40 \mu \mathrm{s}$. Materials maps with zoning (bottom left), reacted HE fraction (top right, scale of 0 to 1 ) and HE pressure (bottom right, scale of 0 to 100 kbar). 

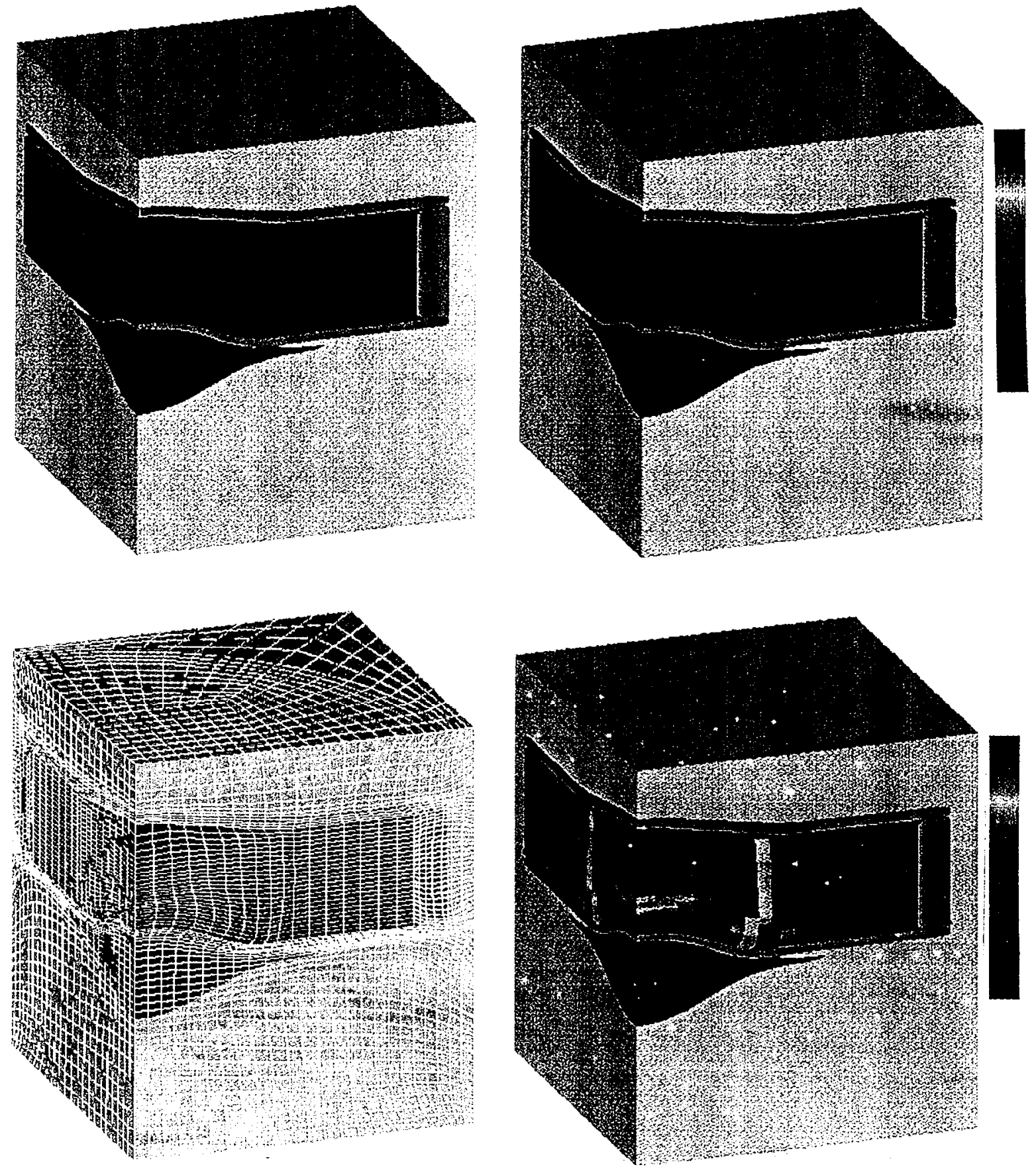

Figure 17: Initial projectile velocity $1.44 \mathrm{~km} / \mathrm{s}$ at $45 \mu \mathrm{s}$. Materials map̃s with zoning (bottom left), reacted $\mathrm{HE}$ fraction (top right, scale of $O$ to 1) and IIE pressure (bottom right, scale of $O$ to 100 kbar). 

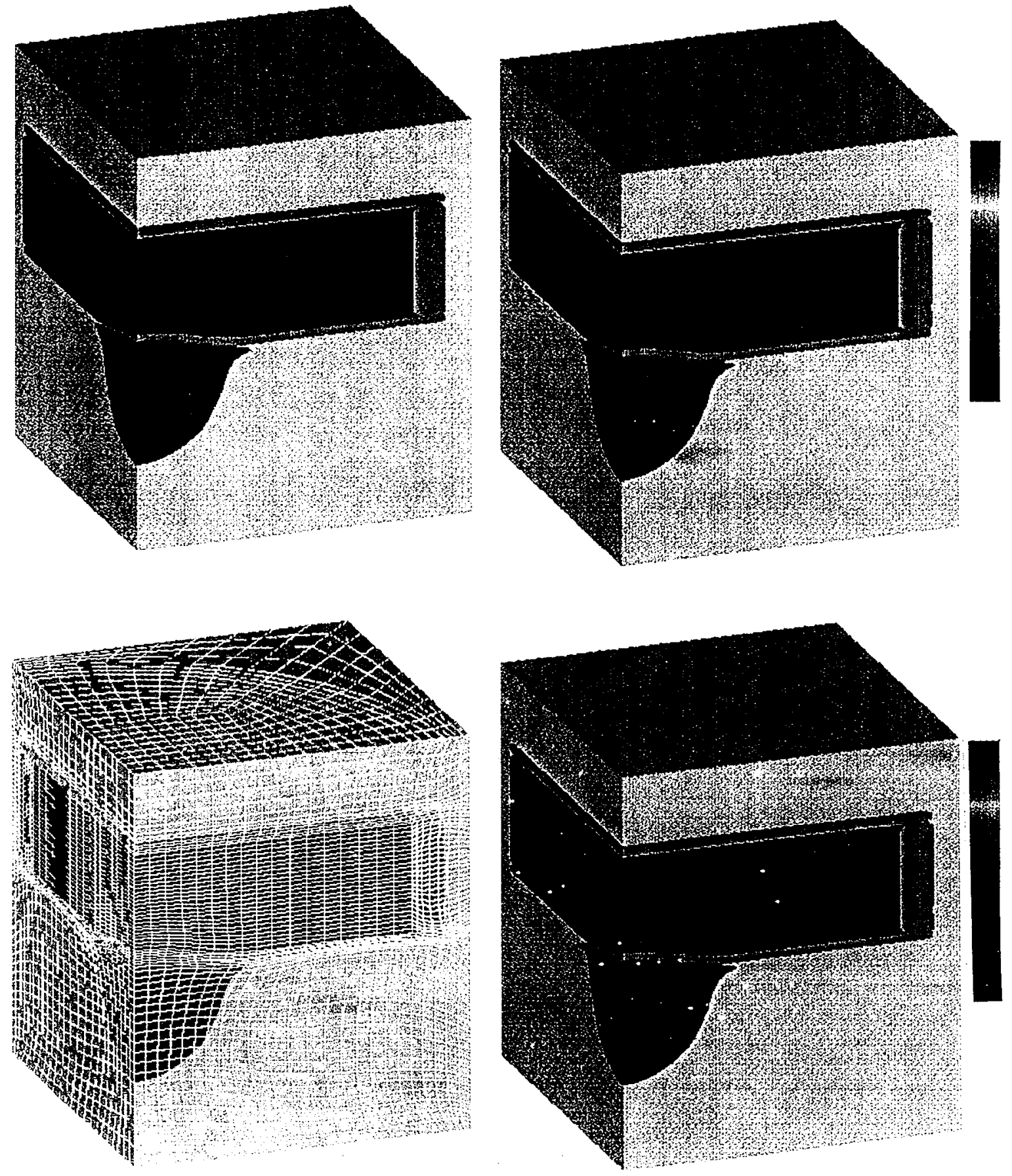

Figure 18: Initial projectile velocity $1.385 \mathrm{~km} / \mathrm{s}$ at $25 \mu \mathrm{s}$. Materials maps with zoning (bottom left), reacted HE fraction (top right, scale of $\mathrm{O}$ to 1 ) and $\mathrm{HE}$ pressure (bottom right, scale of 0 to $100 \mathrm{kbar})$. 

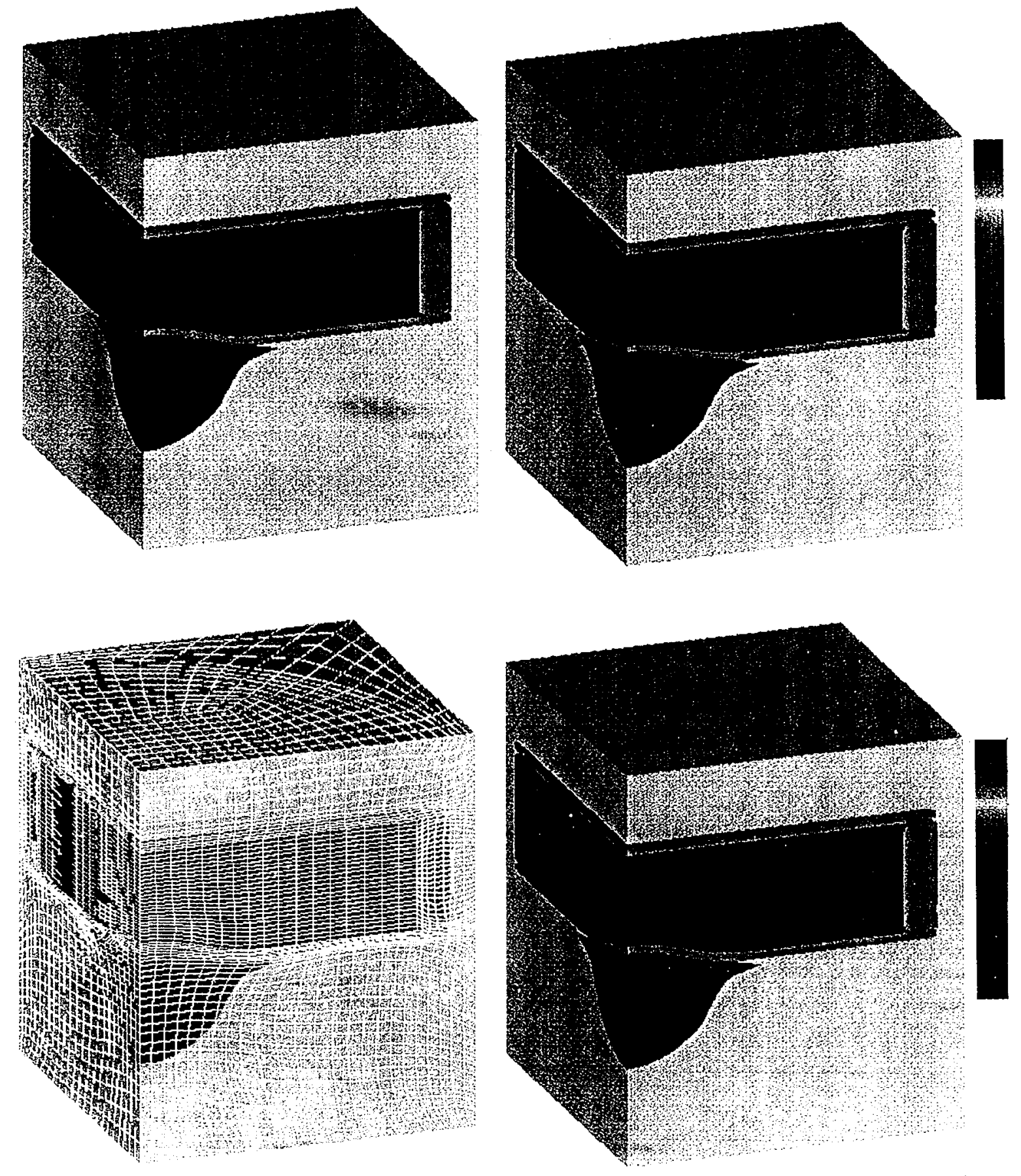

Figure 19: Initial projectile velocity $1.385 \mathrm{~km} / \mathrm{s}$ at $30 \mu \mathrm{s}$. Materials maps with zoning (bottom left), reacted $\mathrm{HE}$ fraction (top right, scale of $\mathrm{O}$ to 1) and $\mathrm{HE}$ pressure (bottom right, scale of 0 to $100 \mathrm{kbar})$. 

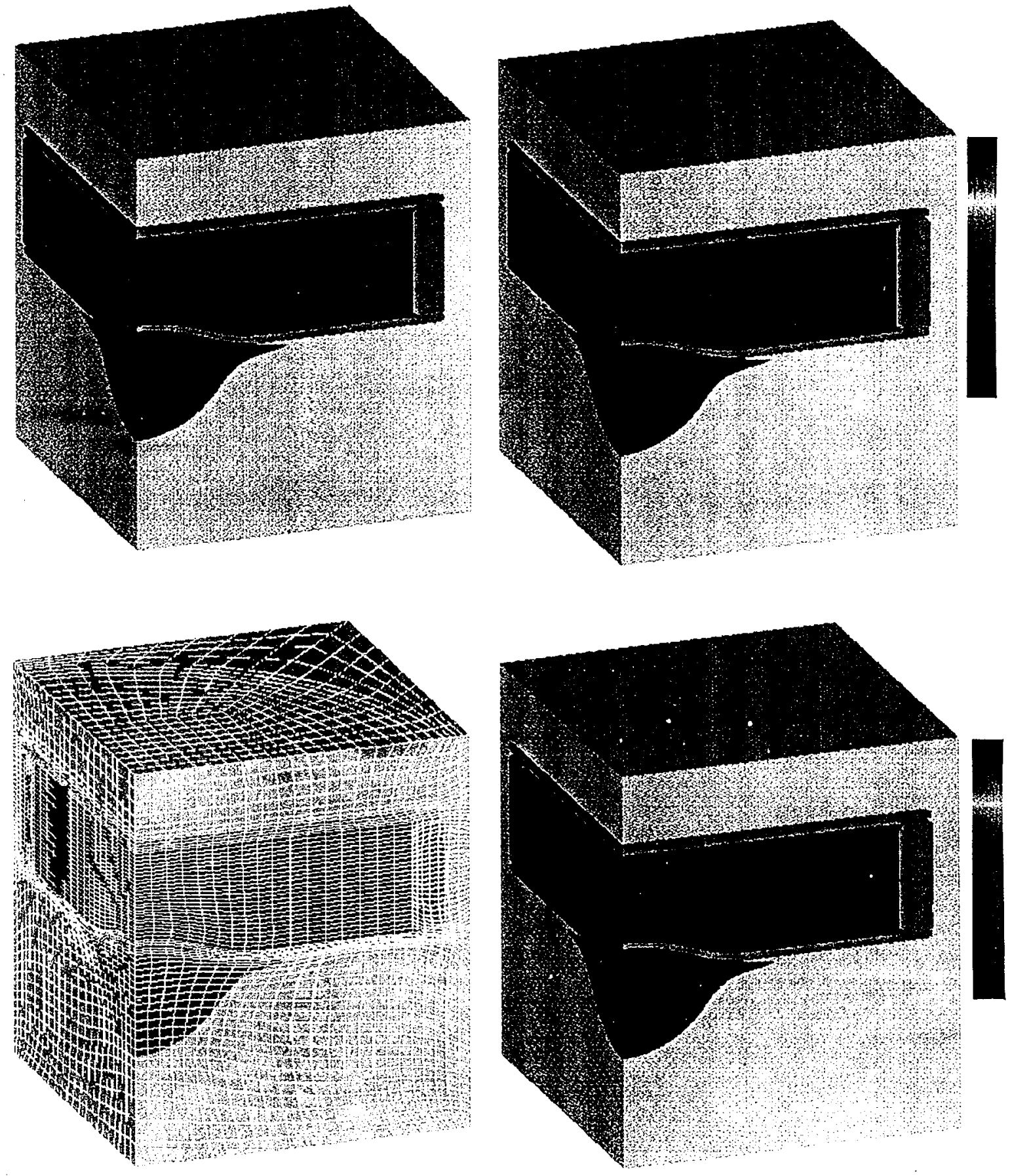

Figure 20: Initial projectile velocity $1.385 \mathrm{~km} / \mathrm{s}$ at $35 \mu \mathrm{s}$. Materials maps with zoning (bottom left), reacted HE fraction (top right, scale of 0 to 1) and HE pressure (bottom right, scale of 0 to $100 \mathrm{kbar}$ ). 

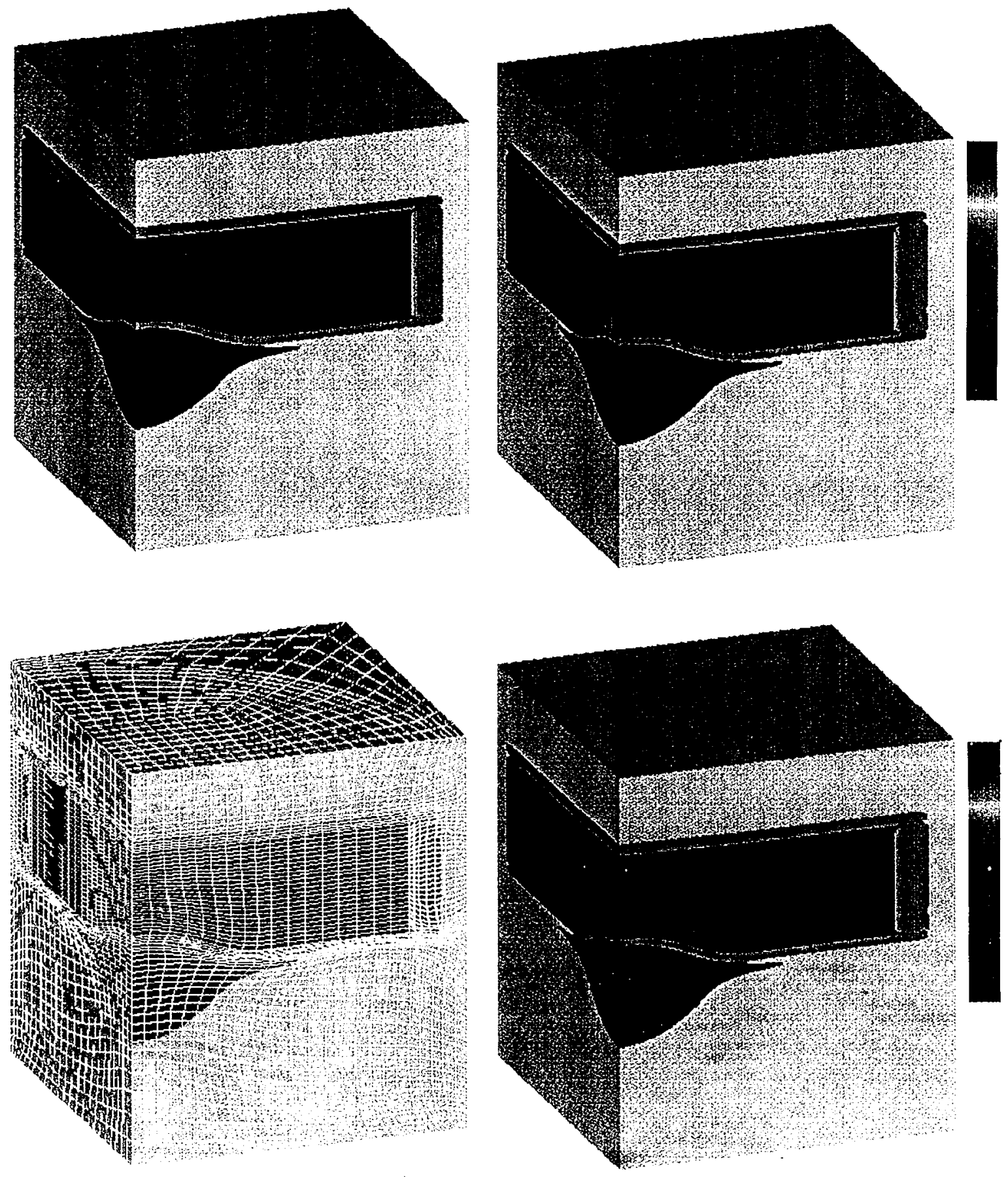

Figure 21: Initial projectile velocity $1.385 \mathrm{~km} / \mathrm{s}$ at $40 \mu \mathrm{s}$. Materials maps with zoning (bottom left), reacted $\mathrm{HE}$ fraction (top right, scale of 0 to 1) and $\mathrm{HE}$ pressure (bottom right, scale of 0 to $100 \mathrm{kbar})$. 

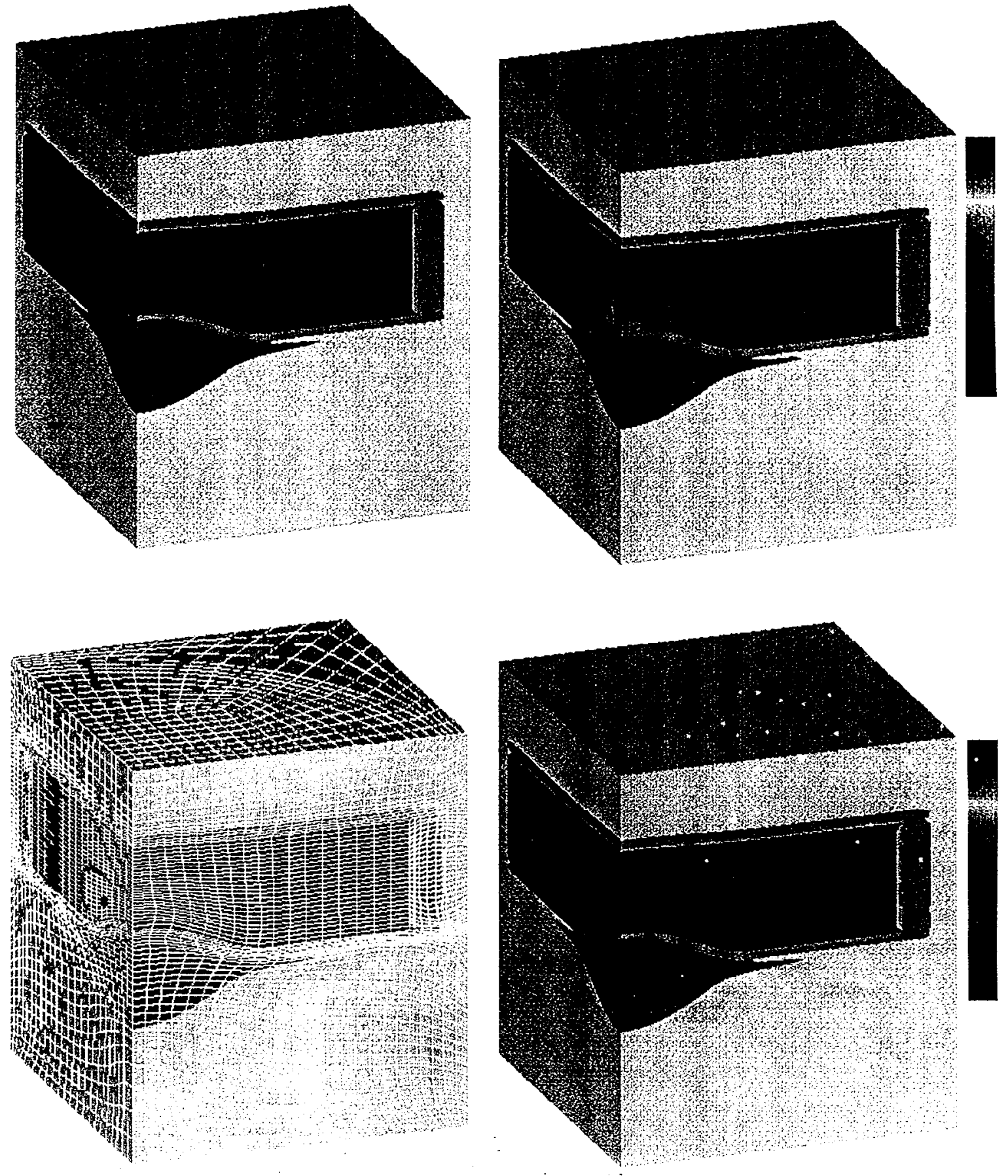

Figure 22: Initial projectile velocity $1.385 \mathrm{~km} / \mathrm{s}$ at $45 \mu \mathrm{s}$. Materials maps with zoning (bottom left), reacted HE fraction (top right, scale of $\mathrm{O}$ to 1 ) and $\mathrm{HE}$ pressure (bottom right, scale of 0 to $100 \mathrm{kbar})$. 

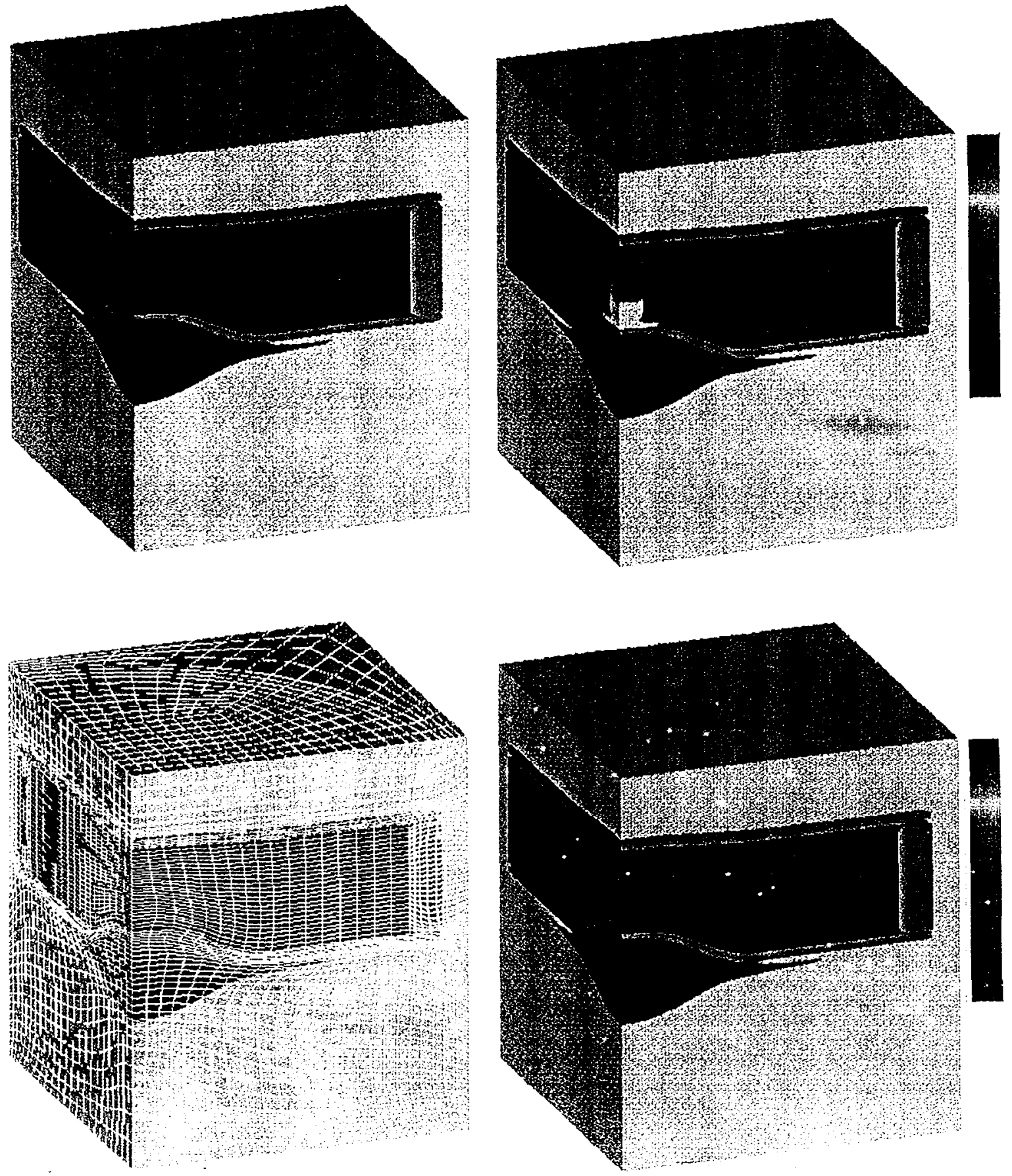

Figure 23: Initial projectile vēlocity $1.385 \mathrm{~km} / \mathrm{s}$ at $50 \mu \mathrm{s}$. Materials maps with zoning (bottom left), reacted HE fraction (top right, scale of $\mathrm{O}$ to 1 ) and $\mathrm{HE}$ pressure (bottom right, scale of 0 to $100 \mathrm{kbar})$. 

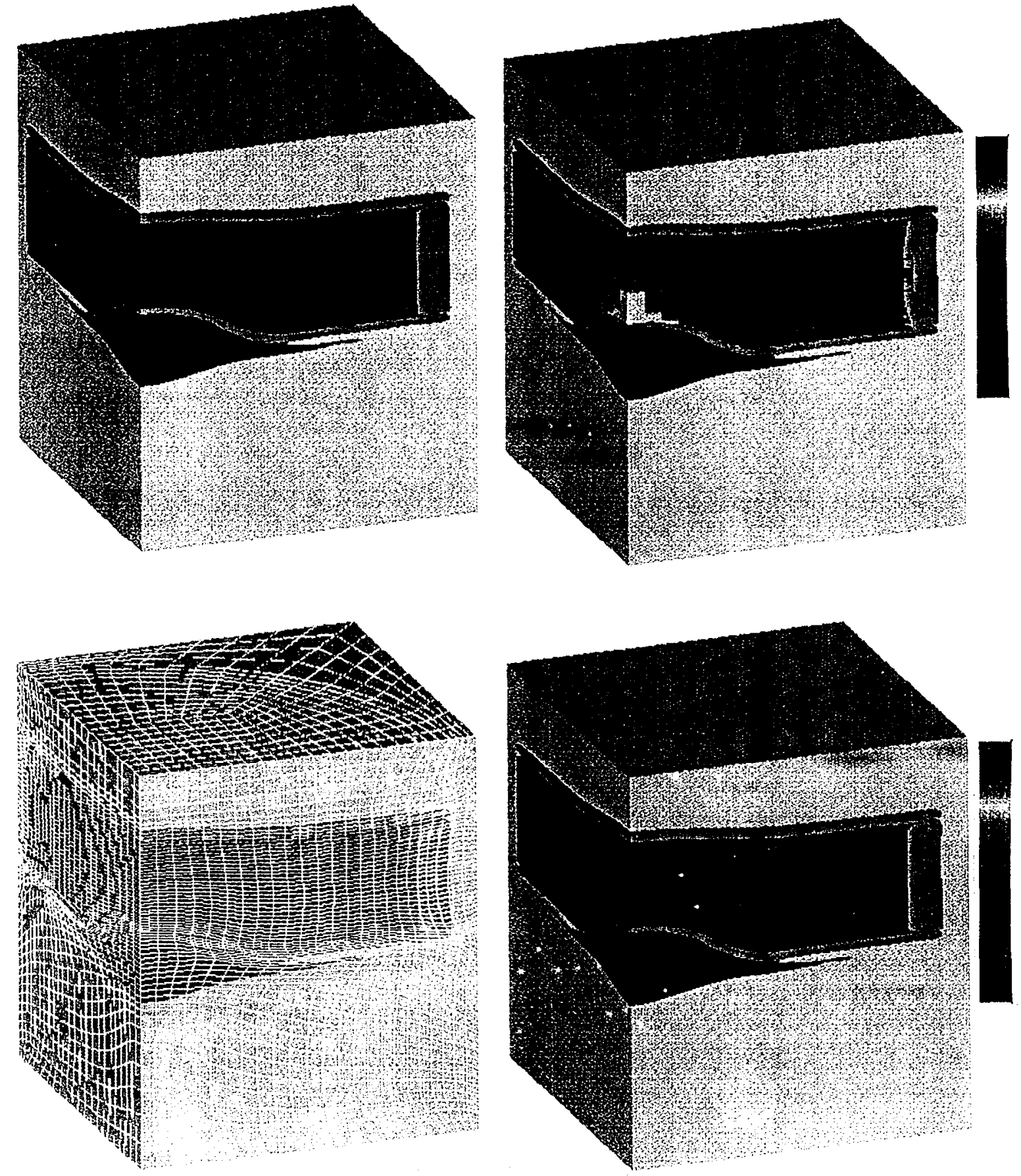

Figure 24: Initial projectile velocity $1.385 \mathrm{~km} / \mathrm{s}$ at $60 \mu$ s. Materials maps with zoning (bottom left), reacted $\mathrm{HE}$ fraction (top right, scale of 0 to 1) and $\mathrm{HE}$ pressure (bottom right, scale of 0 to $100 \mathrm{kbar})$. 

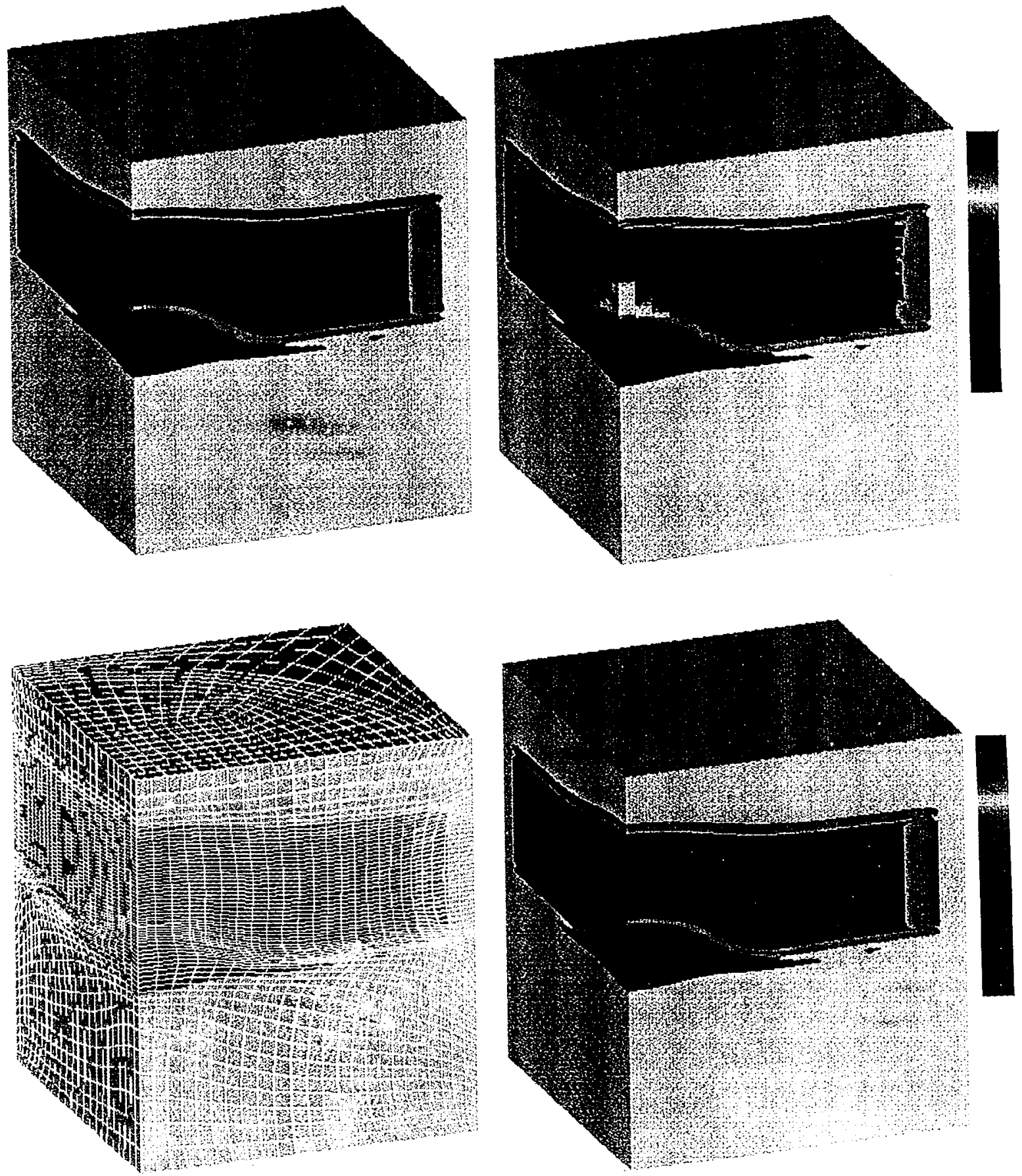

Figure 25: Initial projectile velocity $1.385 \mathrm{~km} / \mathrm{s}$ at $70 \mu \mathrm{s}$. Materials maps with zoning (bottom left), reacted HE fraction (top right, scale of $\mathrm{O}$ to 1 ) and HE pressure (bottom right, scale of 0 to $100 \mathrm{kbar})$. 

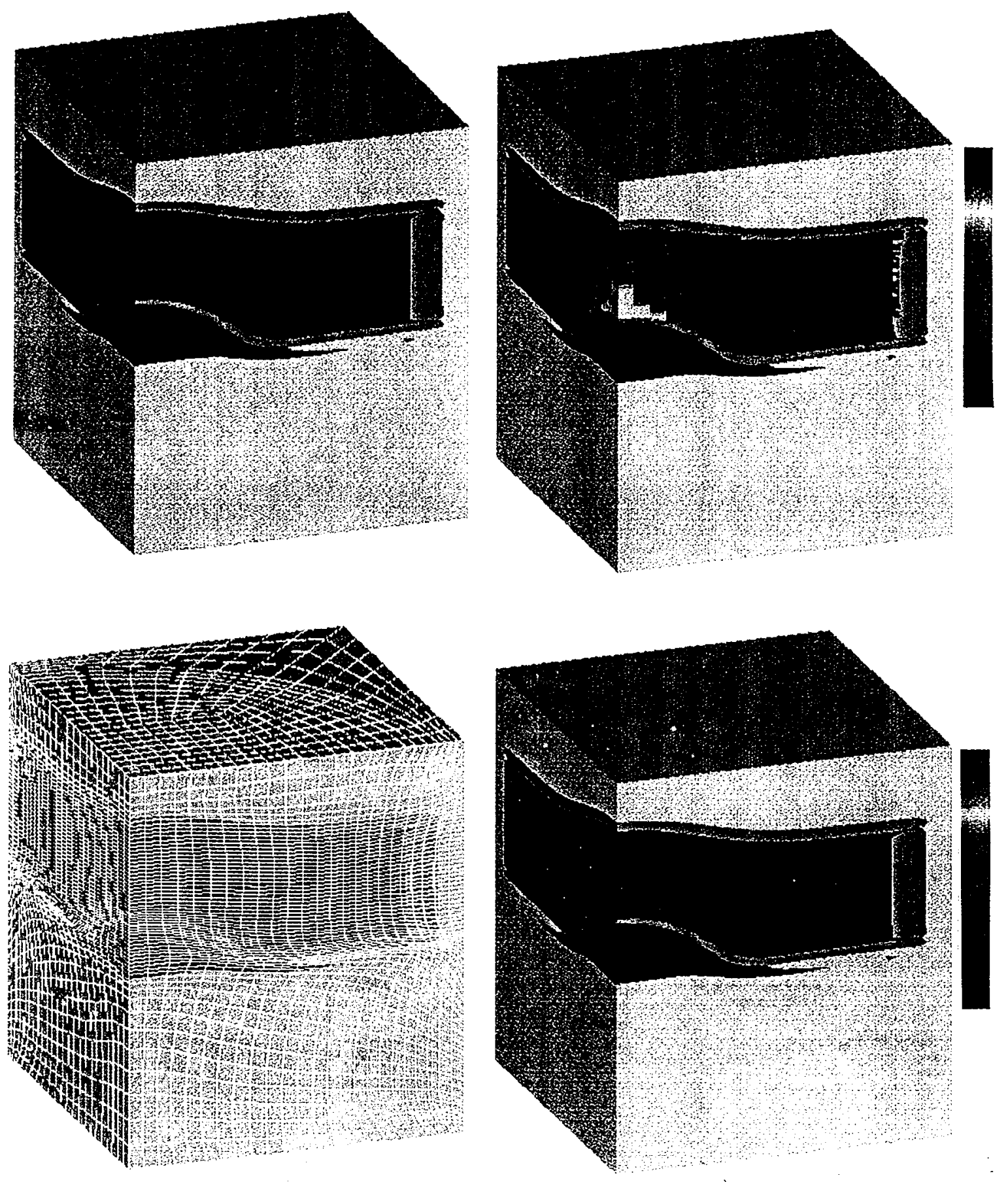

Figure 26: Initial projectile velocity $1.385 \mathrm{~km} / \mathrm{s}$ at $80 \mu \mathrm{s}$. Materials maps with zoning (bottom left), reacted $\mathrm{HE}$ fraction (top right, scale of 0 to 1) and $\mathrm{HE}$ pressure (bottom right, scale of 0 to $100 \mathrm{kbar})$. 

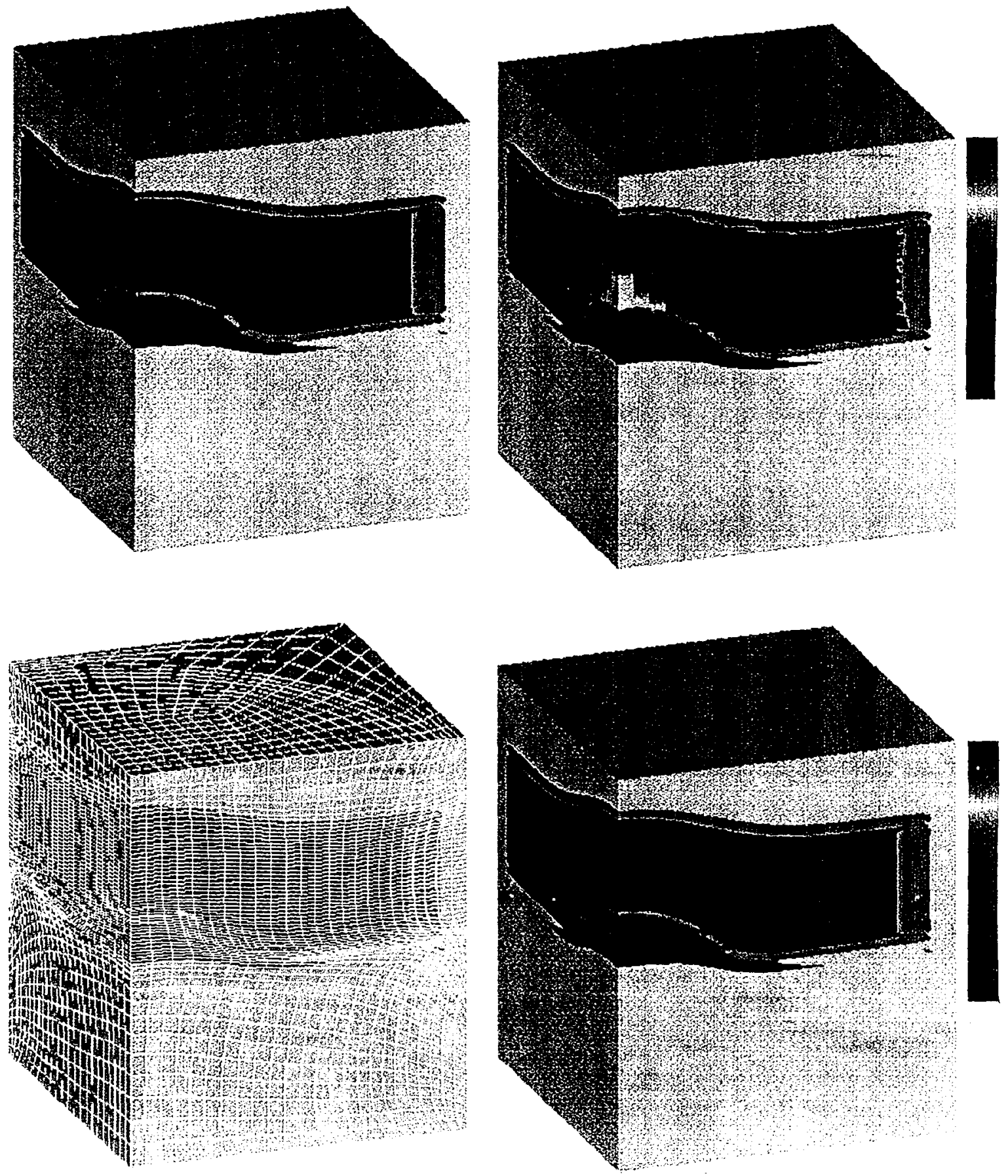

Figure 27: Initial projectile velocity $1.385 \mathrm{~km} / \mathrm{s}$ at $90 \mu \mathrm{s}$. Materials maps with zoning (bottom left), reacted HE fraction (top right, scale of 0 to 1) and $\mathrm{HE}$ pressure (bottom right, scale of 0 to $100 \mathrm{kbar})$. 

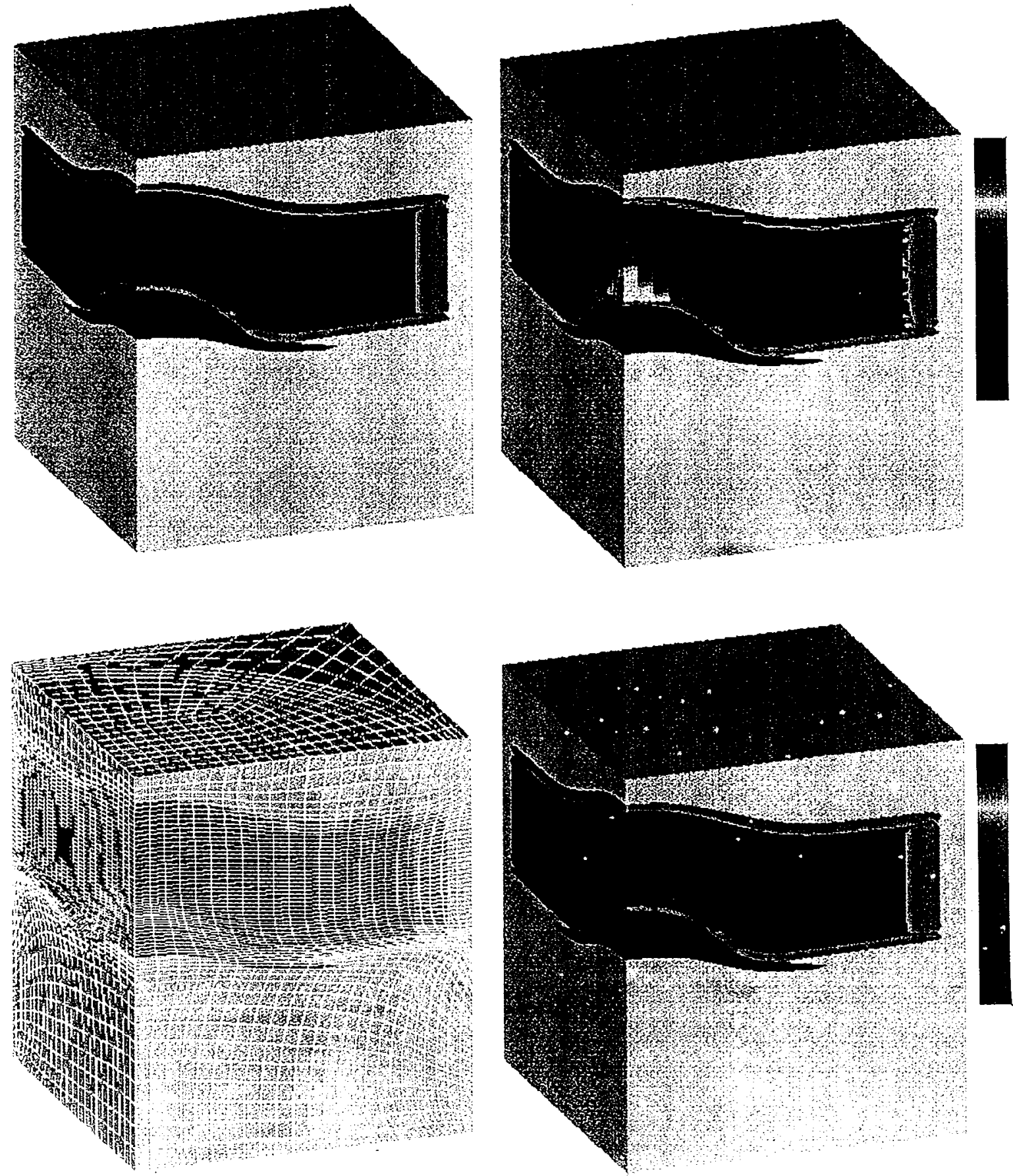

Figure 28: Initial projectile velocity $1.385 \mathrm{~km} / \mathrm{s}$ at $100 \mu \mathrm{s}$. Materials maps with zoning (bottom left), reacted HE fraction (top right, scale of 0 to 1) and HE pressure (bottom right, scale of 0 to $100 \mathrm{kbar}$ ). 



Figure 29: Initial projectile velocity $1.390 \mathrm{~km} / \mathrm{s}$ at $25 \mu \mathrm{s}$. Materials maps with zoning (bottom left), reacted $\mathrm{HE}$ fraction (top right, scale of 0 to 1) and $\mathrm{HE}$ pressure (bottom right, scale of 0 to $100 \mathrm{kbar})$. 



Figure 30: Initial projectile velocity $1.390 \mathrm{~km} / \mathrm{s}$ at $30 \mu \mathrm{s} . \cdot$ Materials maps with zoning (bottom left), reacted $\mathrm{HE}$ fraction (top right, scale of $O$ to 1) and HE pressure (bottom right, scale of 0 to $100 \mathrm{kbar})$. 

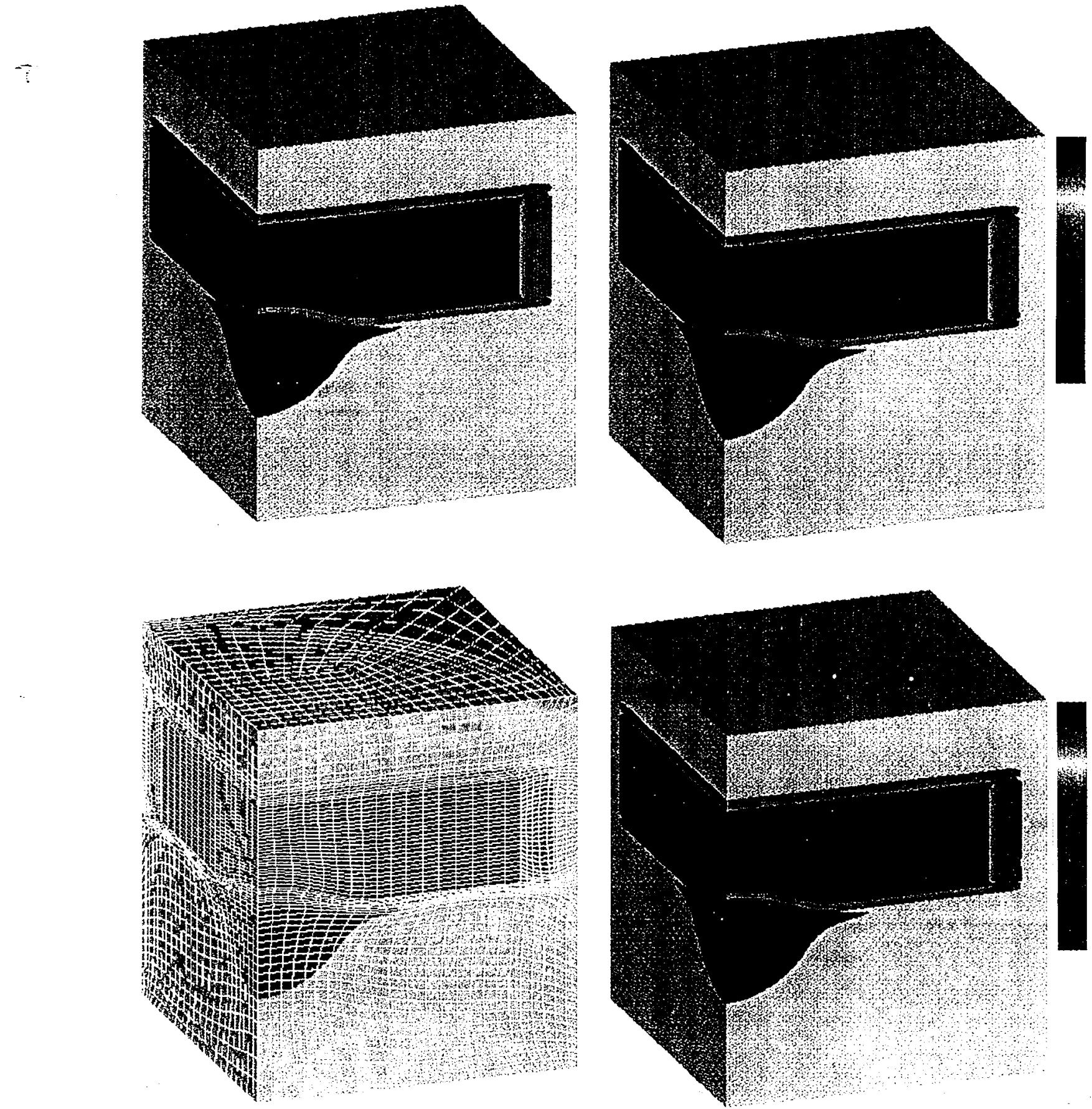

Figure 31: Initial projectile velocity $1.390 \mathrm{~km} / \mathrm{s}$ at $35 \mu \mathrm{s} .{ }^{-1}$ Materials maps with zoning (bottom left), reacted HE fraction (top right, scale of $\mathrm{O}$ to 1 ) and $\mathrm{HE}$ pressure (bottom right, scale of 0 to $100 \mathrm{kbar})$. 

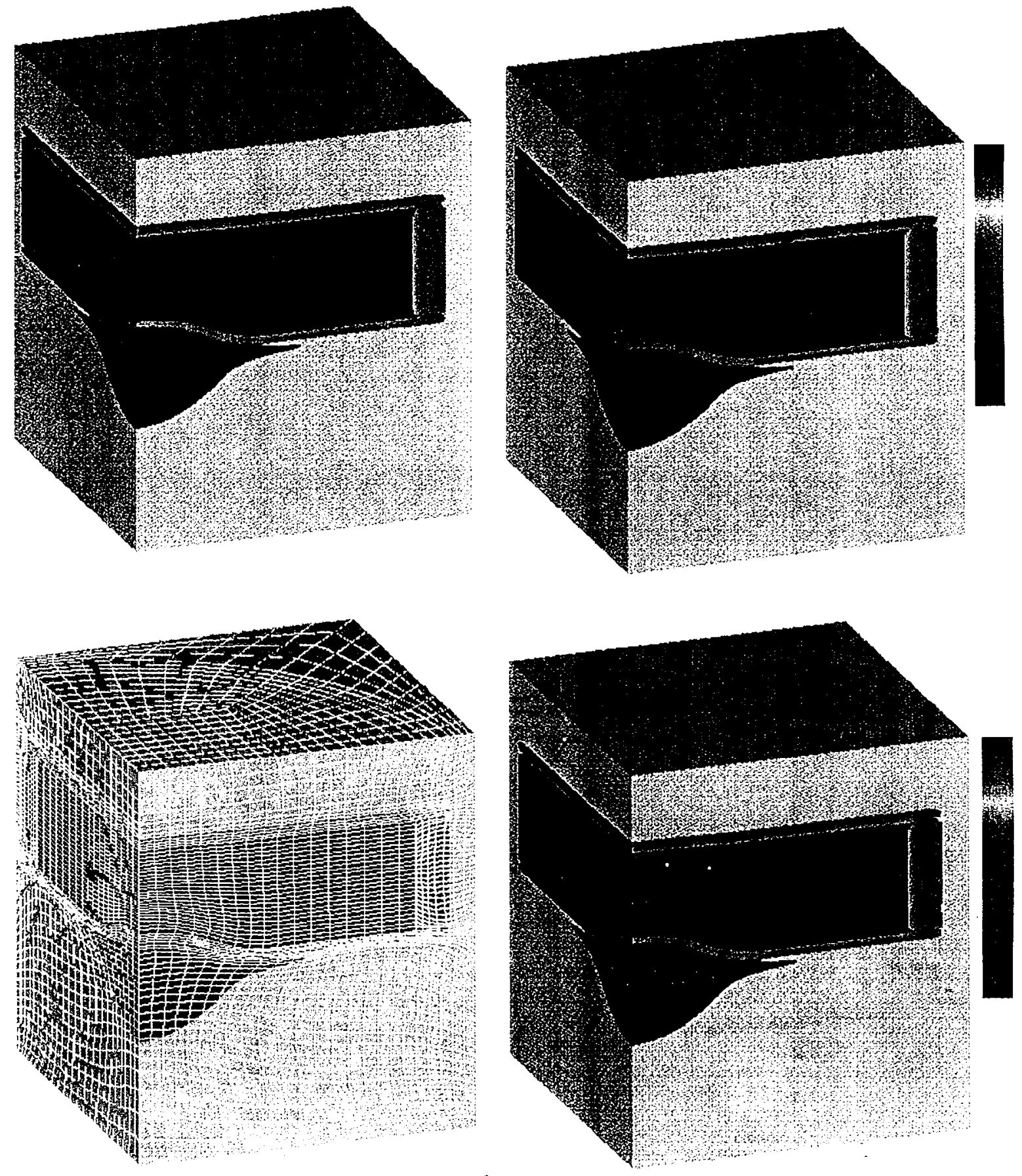

Figure 32: Initial projectile velocity $1.390 \mathrm{~km} / \mathrm{s}$ at $40 \mu \mathrm{s}$. "Materials maps with zoning (bottom left), reacted $\mathrm{HE}$ fraction '(top right, scale of $\mathrm{O}$ to 1 ) and $\mathrm{HE}$ pressure (bottom right, scale of 0 to $100 \mathrm{kbar}$ ). 

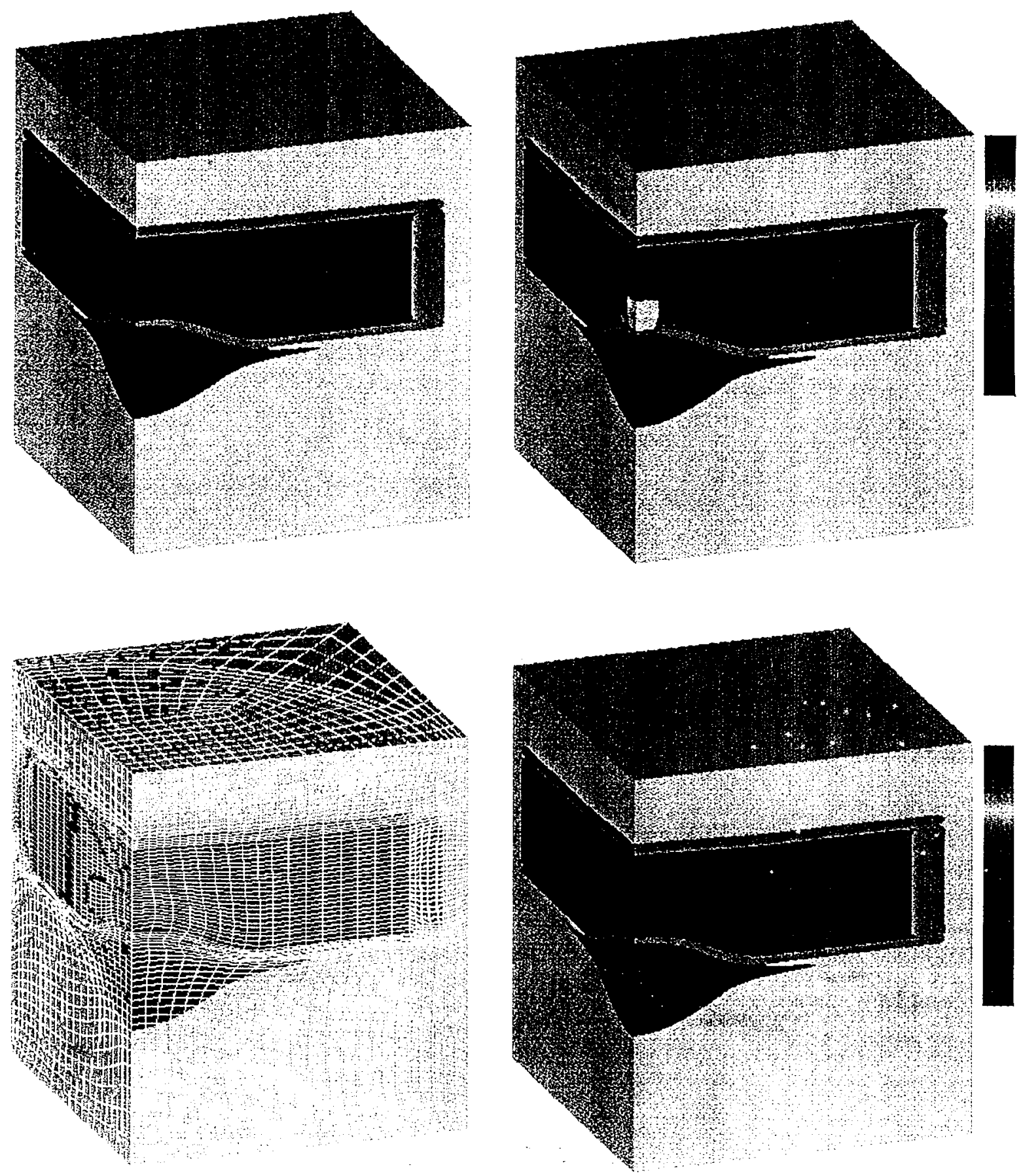

Figure 33: Initial projectile velocity $1.390 \mathrm{~km} / \mathrm{s}$ at $45 \mu \mathrm{s}$. Materials maps with zoning (bottom left), reacted $\mathrm{HE}$ fraction (top right, scale of $O$ to 1) and HE pressure (bottom right, scale of 0 to $100 \mathrm{kbar}$ ). 



Figure 34: Initial projectile velócity $1.390 \mathrm{~km} / \mathrm{s}$ at $50 \mu \mathrm{s}$. Materials maps with zoning (bottom left), reacted $\mathrm{HE}$ fraction (top right, scale of $\mathrm{O}$ to 1) and $\mathrm{HE}$ pressure (bottom right, scale of 0 to $100 \mathrm{kbar})$. 

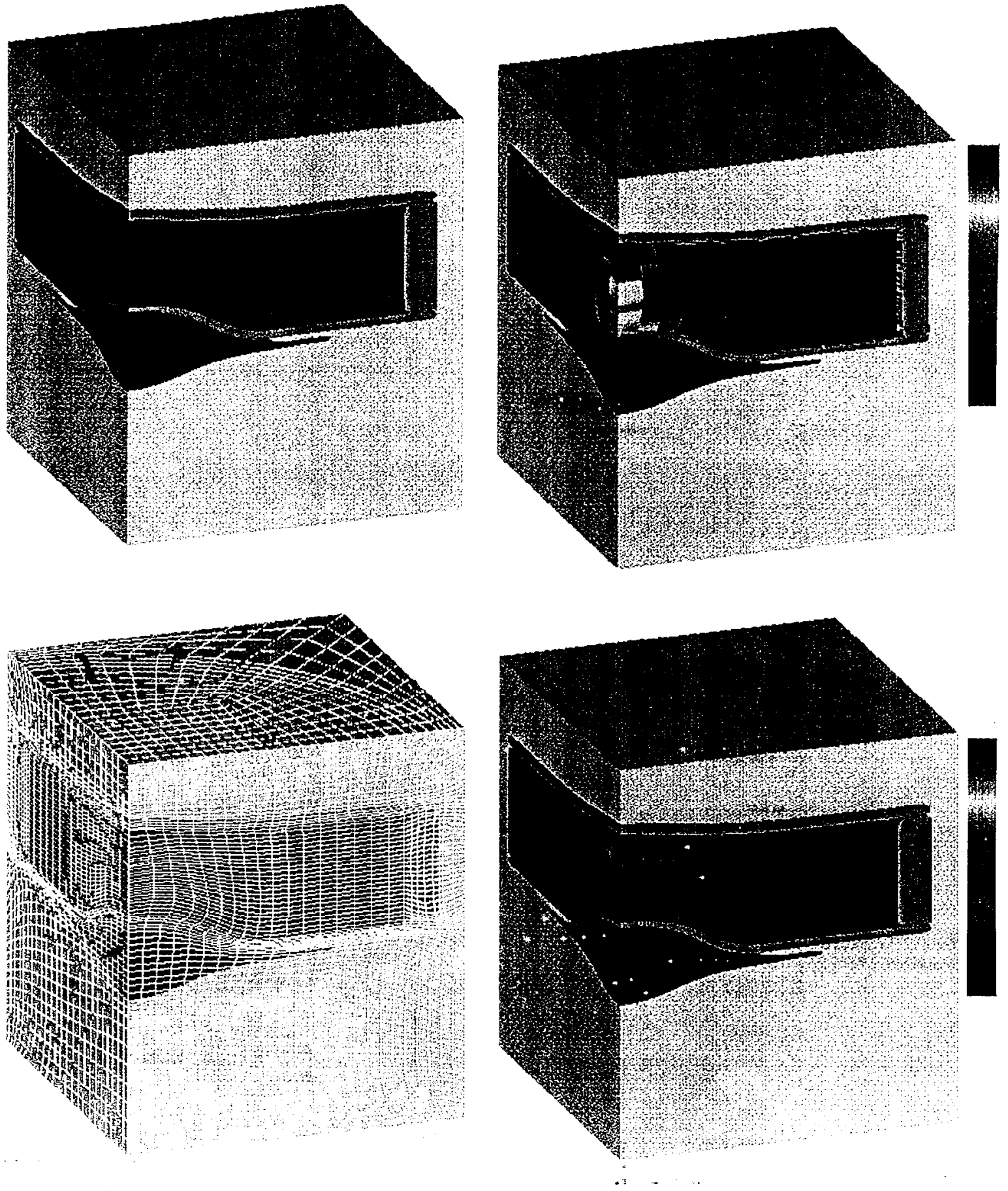

Figure 35: Initial projectile velocity $1.390 \mathrm{~km} / \mathrm{s}$ at $55 \mu \mathrm{s}$. Materials maps with zoning (bottom left), reacted $\mathrm{HE}$ fraction (top right, scale of $O$ to 1 ) and $\mathrm{HE}$ pressure (bottom right, scale of 0 to $100 \mathrm{kbar})$. 

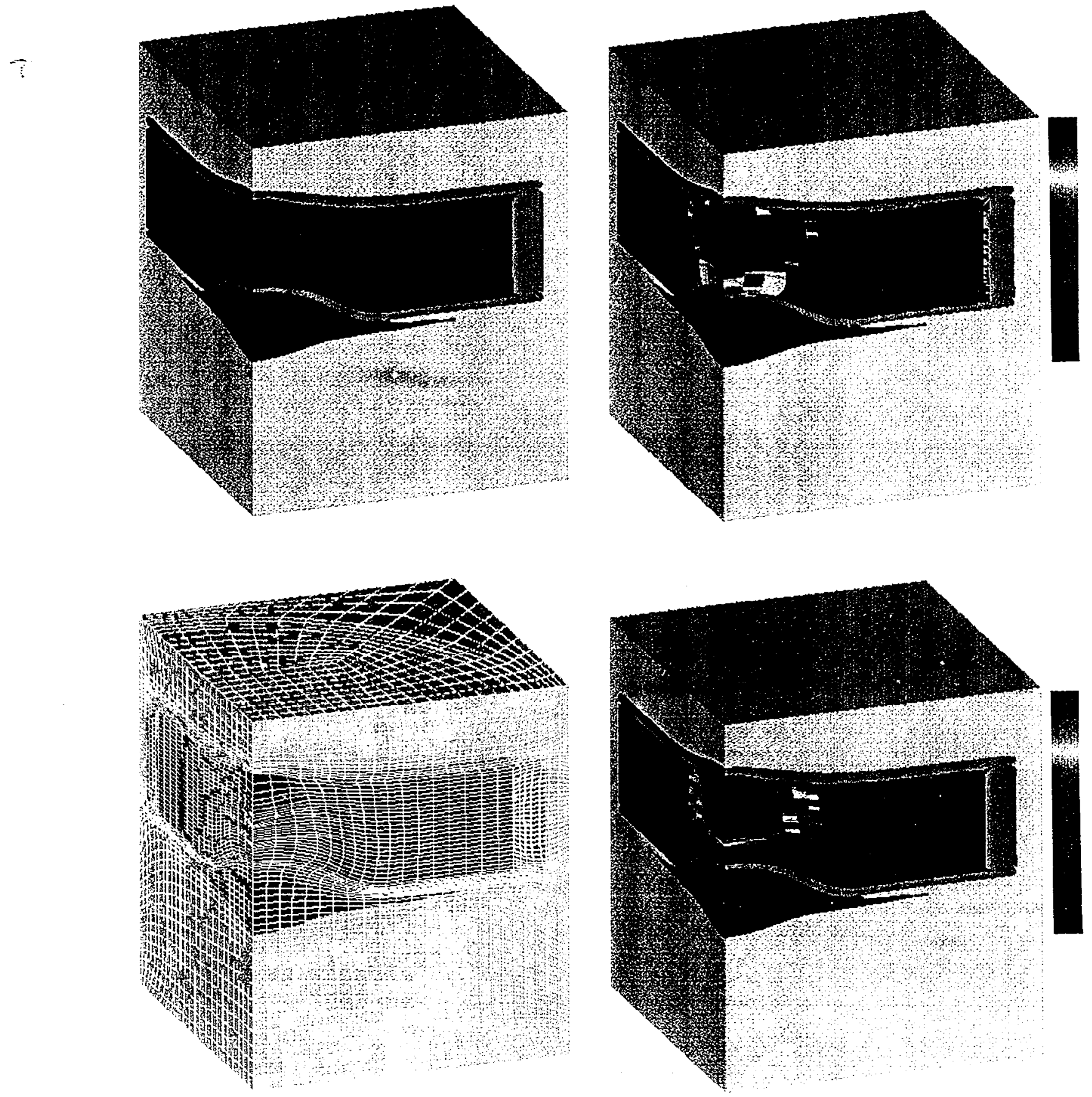

Figure 36: Initial projectile velocity $1.390 \mathrm{~km} / \mathrm{s}$ at $60 \mu \mathrm{s}$. Materials maps with zoning (bottom left), reacted $\mathrm{HE}$ fraction (top right, scale of $\mathrm{O}$ to 1 ) and $\mathrm{HE}$ pressure (bottom right, scale of 0 to $100 \mathrm{kbar})$. 



Figure 37: Initial projectile velocity $1.390 \mathrm{~km} / \mathrm{s}$ at $65 \mu \mathrm{s}$. Materials maps with zoning (bottom left), reacted HE fraction (top right, scale of 0 to 1) and HE pressure (bottom right, scale of 0 to $100 \mathrm{kbar})$. 
In the standard test problem calculations the $\mathrm{HE}$ is devoid of mixed zones until late in the calculation, long after projectile impact. In many calculations mixed zones are present from the very beginning. Versions of ALE3D up to 2.8.3 produced different detonation thresholds for the test problem depending on whether mixed zones were present in the $\mathrm{HE}$ at projectile impact. The detonation threshold was 7 to 8 percent higher when mixed zones were present. This was traced to inadvertent inhibition of $\mathrm{HE}$ burn in mixed zones and was remedied with version 2.8.18. We examine the effect of allowing mixed zones in the HE prior to projectile impact. Allowing mixed zones in the HE brings potential dependence of the IGM on whether pressure relaxation is turned on in mixed zones. The default setting in ALE3D is to have this relaxation turned off. The runs discussed in the previous section were carried out with the pressure relaxation in mixed zones turned off, but this has no effect on the calculation since the $\mathrm{HE}$ was made up of clean zones until late times. We have established that turning off pressure relaxation in mixed zones produces more accurate transport of lateral solid material momentum across a void or air, when coarse zoning is used. Platform limitations often force the use of coarse zoning in full scale impact calculations, so many problems are run with pressure relaxation in mixed zones turned off. We examine the effect of turning pressure relaxation in mixed zones on. Finally, the runs discussed in the previous section were carried out with the default value of rlxginit i.e. 0 . This means that mesh relaxation was applied to the nodal positions at the end of the cycle. Many problems involving penetration of one material into others run better with rlxginit set to one which applies relaxation to the nodal positions at the beginning of the cycle. In our experience many runs that gets into trouble can be continued by changing the value of rlxginit. We examine the effect of rlxginit.

We carried out the sensitivity study by varying the projectile velocity by $0.005 \mathrm{~km} / \mathrm{s}$ until we found runs that just produce detonation and others that are just short of it. The results are shown in Table 1. They are heartening, given that the detonation threshold varies by $2.5 \%$ across the entire space. There is very little dependence on whether mixed zones are present in the HE at projectile impact, little dependence on turning pressure relaxation off, and little dependence on rlxginit. 


\section{Table 1}

\section{Dependence of HE behavior on model initial conditions}

\begin{tabular}{|c|c|c|}
\hline $\begin{array}{l}\text { Initially clean zones in } \mathrm{HE} \\
\text { rlxginit }=0\end{array}$ & $\begin{array}{l}V=1.385 \mathrm{~km} / \mathrm{s} \\
V=1.390 \mathrm{~km} / \mathrm{s}\end{array}$ & $\begin{array}{l}\text { Insignificant } \mathrm{HE} \text { reaction at } 100 \mu \mathrm{s} \\
\text { Detonation at } 60 \mu \mathrm{s}\end{array}$ \\
\hline $\begin{array}{l}\text { Initially clean zones in } \mathrm{HE} \\
\text { rlxginit }=1\end{array}$ & $\begin{array}{l}\mathrm{V}=1.395 \mathrm{~km} / \mathrm{s} \\
\mathrm{V}=1.400 \mathrm{~km} / \mathrm{s}\end{array}$ & $\begin{array}{l}\text { Insignificant } \mathrm{HE} \text { reaction at } 100 \mu \mathrm{s} \\
\text { Detonation at } 55 \mu \mathrm{s}\end{array}$ \\
\hline $\begin{array}{l}\text { Mixed zones in } \mathrm{HE} \\
\text { Pressure relaxation off } \\
\text { rlxginit=0 }\end{array}$ & $\begin{array}{l}\mathrm{V}=1.370 \mathrm{~km} / \mathrm{s} \\
\mathrm{V}=1.375 \mathrm{~km} / \mathrm{s}\end{array}$ & $\begin{array}{l}\text { Insignificant } \mathrm{HE} \text { reaction at } 100 \mu \mathrm{s} \\
\text { Detonation at } 60 \mu \mathrm{s}\end{array}$ \\
\hline $\begin{array}{l}\text { Mixed zones in } \mathrm{HE} \\
\text { Pressure relaxation off } \\
\text { rlxginit=1 }\end{array}$ & $\begin{array}{l}\mathrm{V}=1.360 \mathrm{~km} / \mathrm{s} \\
\mathrm{V}=1.365 \mathrm{~km} / \mathrm{s}\end{array}$ & $\begin{array}{l}\text { Insignificant } \mathrm{HE} \text { reaction at } 100 \mu \mathrm{s} \\
\text { Detonation at } 45 \mu \mathrm{s}\end{array}$ \\
\hline $\begin{array}{l}\text { Mixed zones in } \mathrm{HE} \\
\text { Pressure relaxation on } \\
\text { rlxginit }=0\end{array}$ & $\begin{array}{l}\mathrm{V}=1.380 \mathrm{~km} / \mathrm{s} \\
\mathrm{V}=1.385 \mathrm{~km} / \mathrm{s}\end{array}$ & $\begin{array}{l}\text { Insignificant } \mathrm{HE} \text { reaction at } 100 \mu \mathrm{s} \\
\text { Detonation at } 50 \mu \mathrm{s}\end{array}$ \\
\hline $\begin{array}{l}\text { Mixed zones in } \mathrm{HE} \\
\text { Pressure relaxation on } \\
\text { rlxginit=1 }\end{array}$ & $\begin{array}{l}\mathrm{V}=1.380 \mathrm{~km} / \mathrm{s} \\
\mathrm{V}=1.385 \mathrm{~km} / \mathrm{s}\end{array}$ & $\begin{array}{l}\text { Insignificant } \mathrm{HE} \text { reaction at } 100 \mu \mathrm{s} \\
\text { Detonation at } 55 \mu \mathrm{s}\end{array}$ \\
\hline
\end{tabular}

rlxginit $=0$ default setting, relaxation starting point is node position at end of cycle.

rlxginit $=1$ relaxation starting point is node position at beginning of cycle.

Pressure relaxation on : default setting, materials in mixed zones forced to same pressure.

Pressure relaxation off : materials in mixed zones allowed to remain at different pressures. 


\section{Comparison with CALE}

The original CALE calculations modeling the experiments were performed with much finer zoning than that used in our test problems. We performed CALE runs with zoning essentially identical to that used in the test problems. In CALE pressure relaxation is always on, but this should have no effect since the HE is devoid of mixed zones. A run with $1.380 \mathrm{~km} / \mathrm{s}$ initial projectile velocity produces $\mathrm{HE}$ burn which dies down to the point where insignificant $\mathrm{HE}$ reaction takes place at $100 \mu \mathrm{s}$. A run with 1.385 initial projectile velocity results in a detonation at $60 \mu \mathrm{s}$. This is in excellent agreement with the ALE3D runs reported above.

\section{Test Problems Input}

The true grid mesh generator input and the ALE3D inputs are listed in the appendix.

\section{References}

1. Lee, E.L. and Tarver, C.M., "Phenomenological Model of Shock Initiation in Heterogeneous Explosives," Phys. Fluids, Vol. 23, Nov. 12, 1980, pp 2362-2372.

2. Murphy, M.J., Lee, E.L., Weston, A.M. and Williams, A.E., "Modeling Shock Initiation in Composition B", $10^{\text {th }}$ Symposium on Detonation, ONR33395-12, 1993m pp 963-970.

3. Gerassimenko, M. and Otero, I., "Validation of Reactive Flow HE Model in the ALE3D Code", DDV-94-0042, 1994. 
APPENDIX 


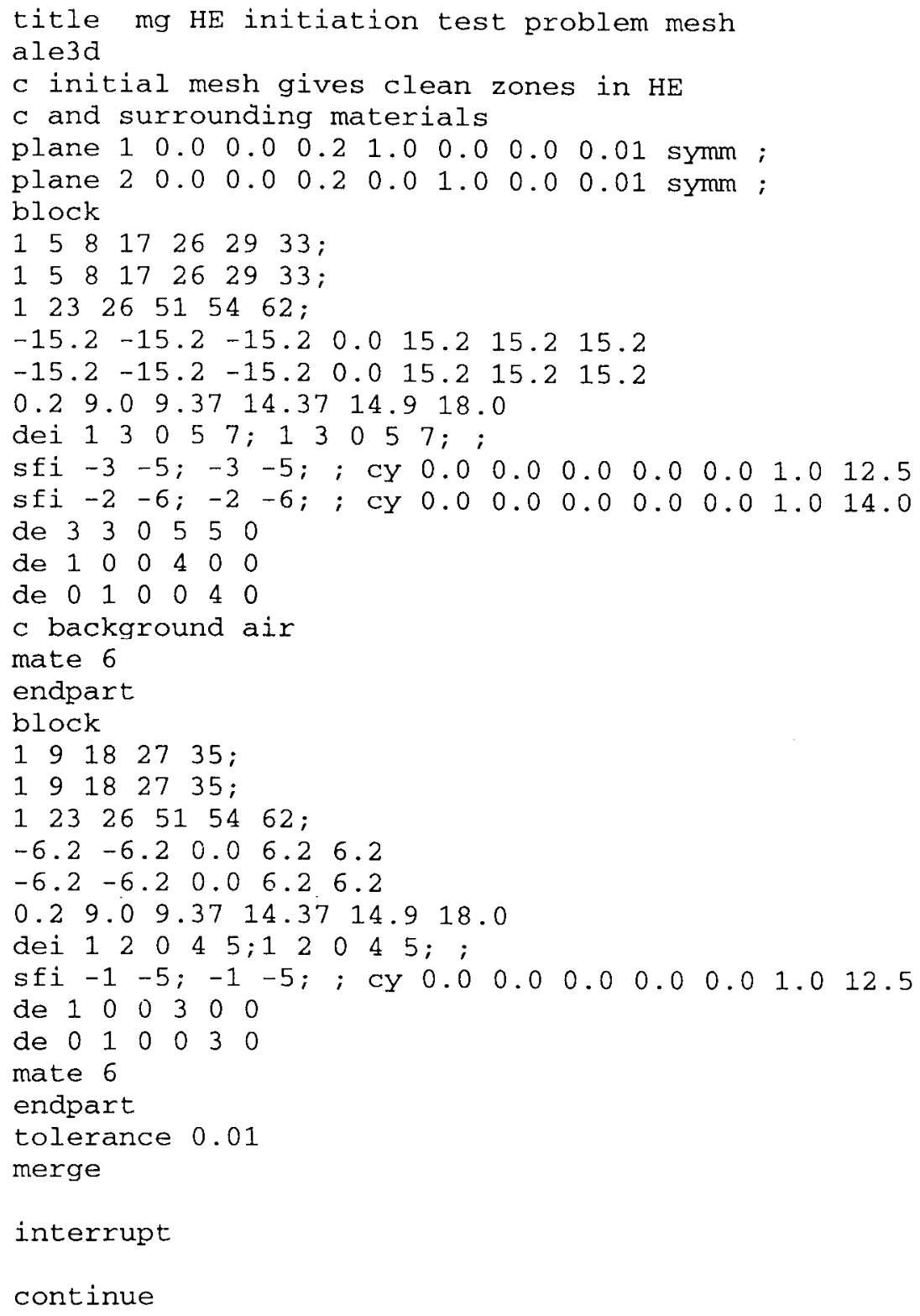




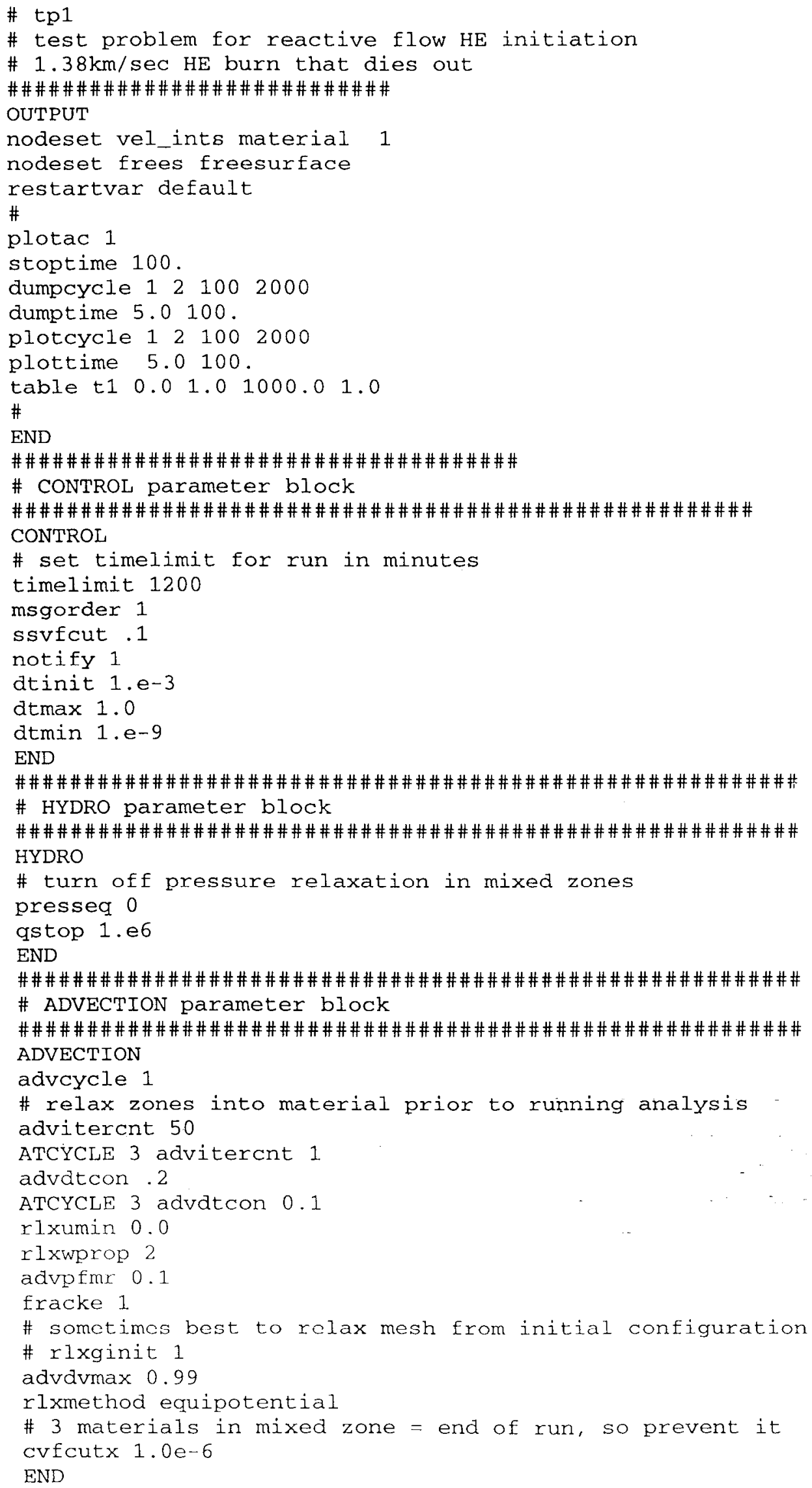




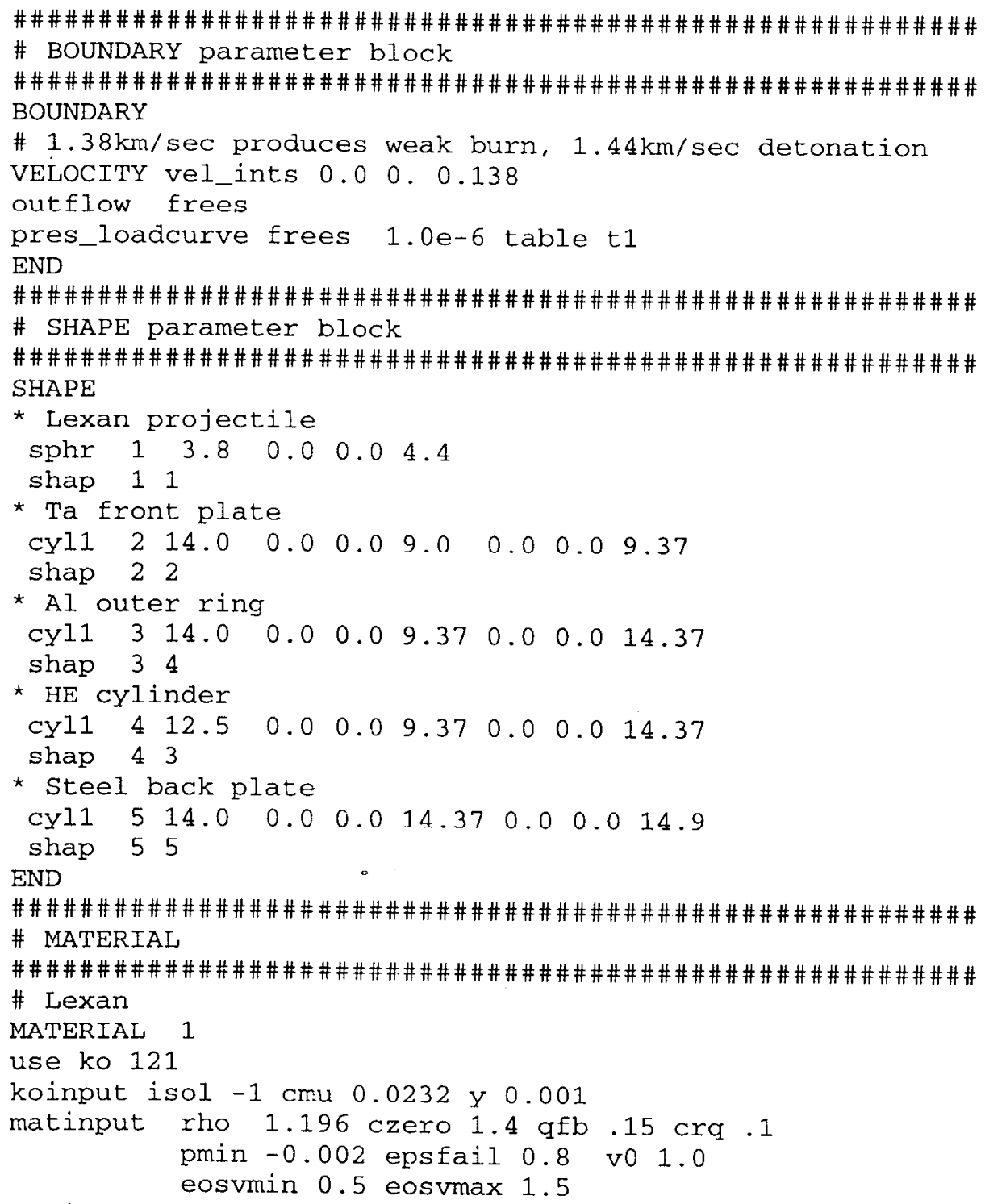


bhe 0.0

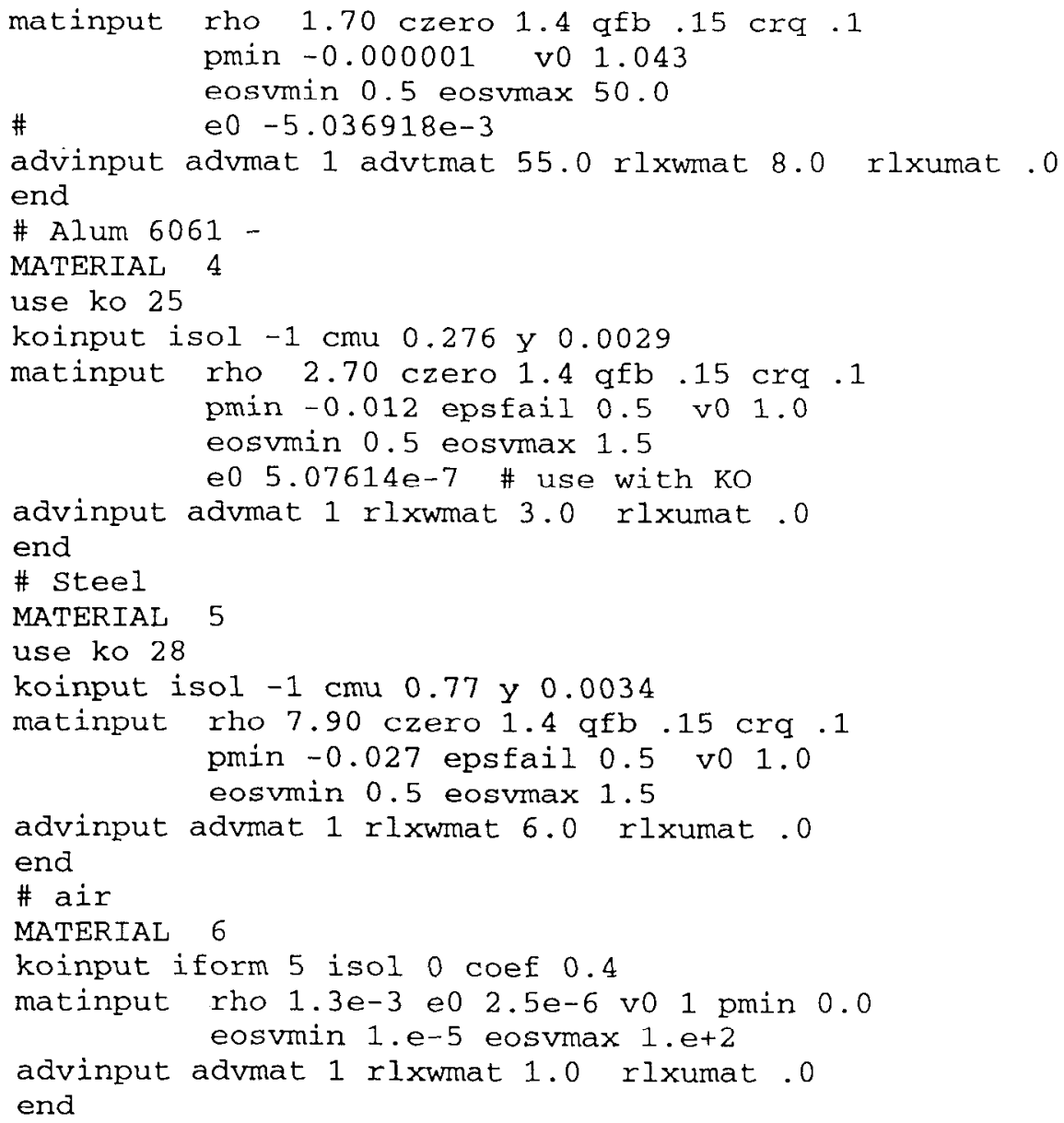




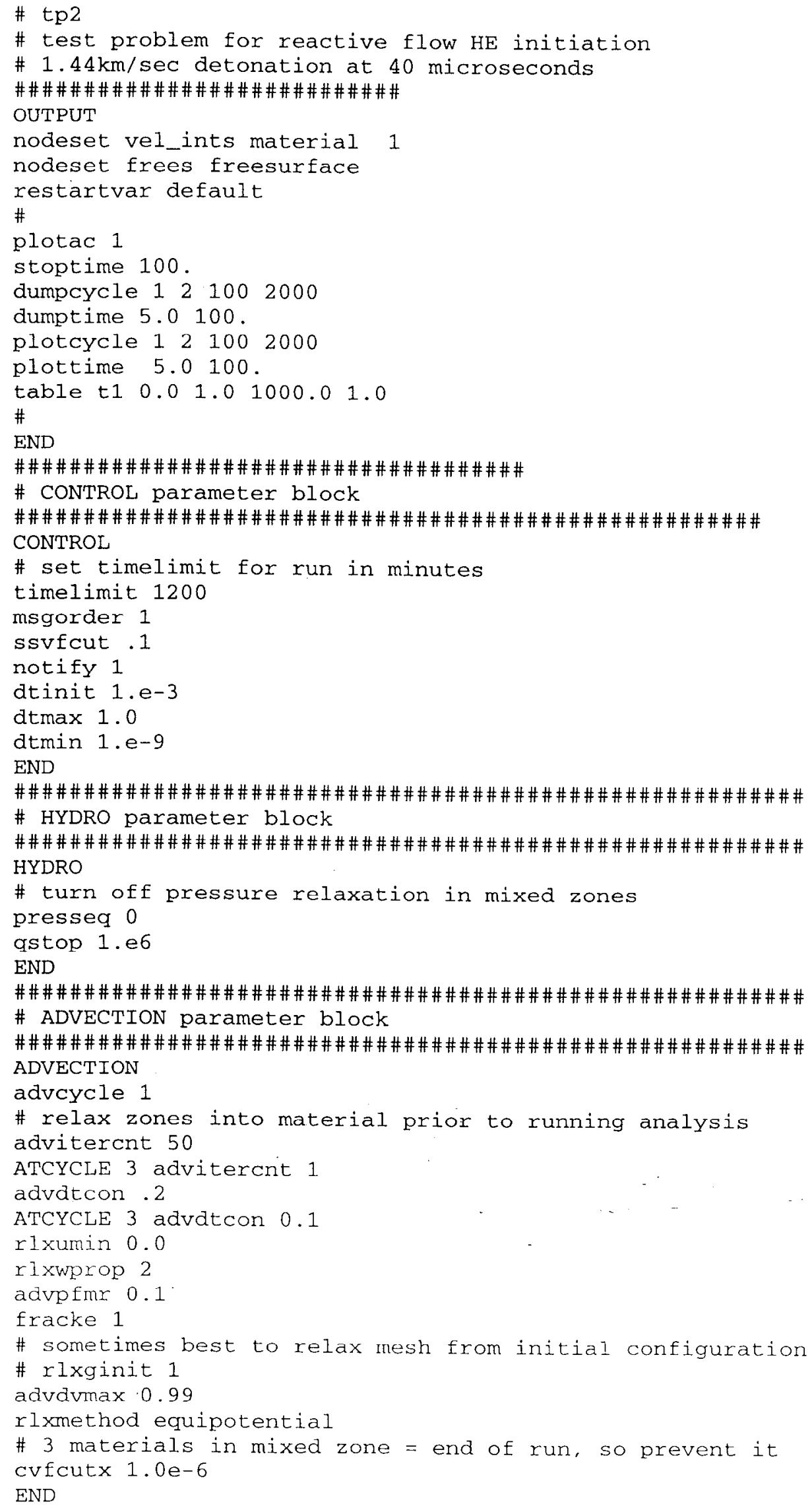




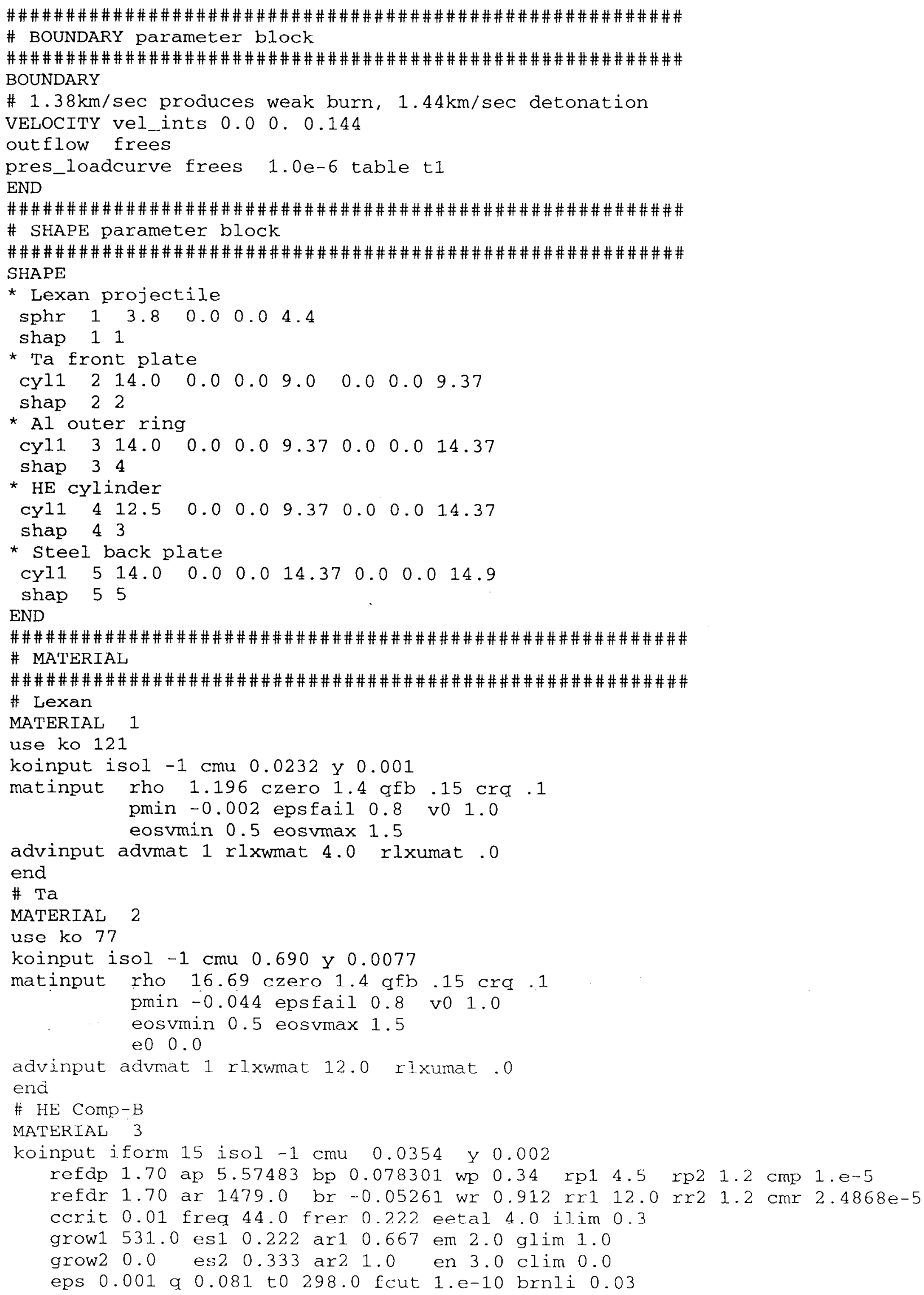


bhe 0.0

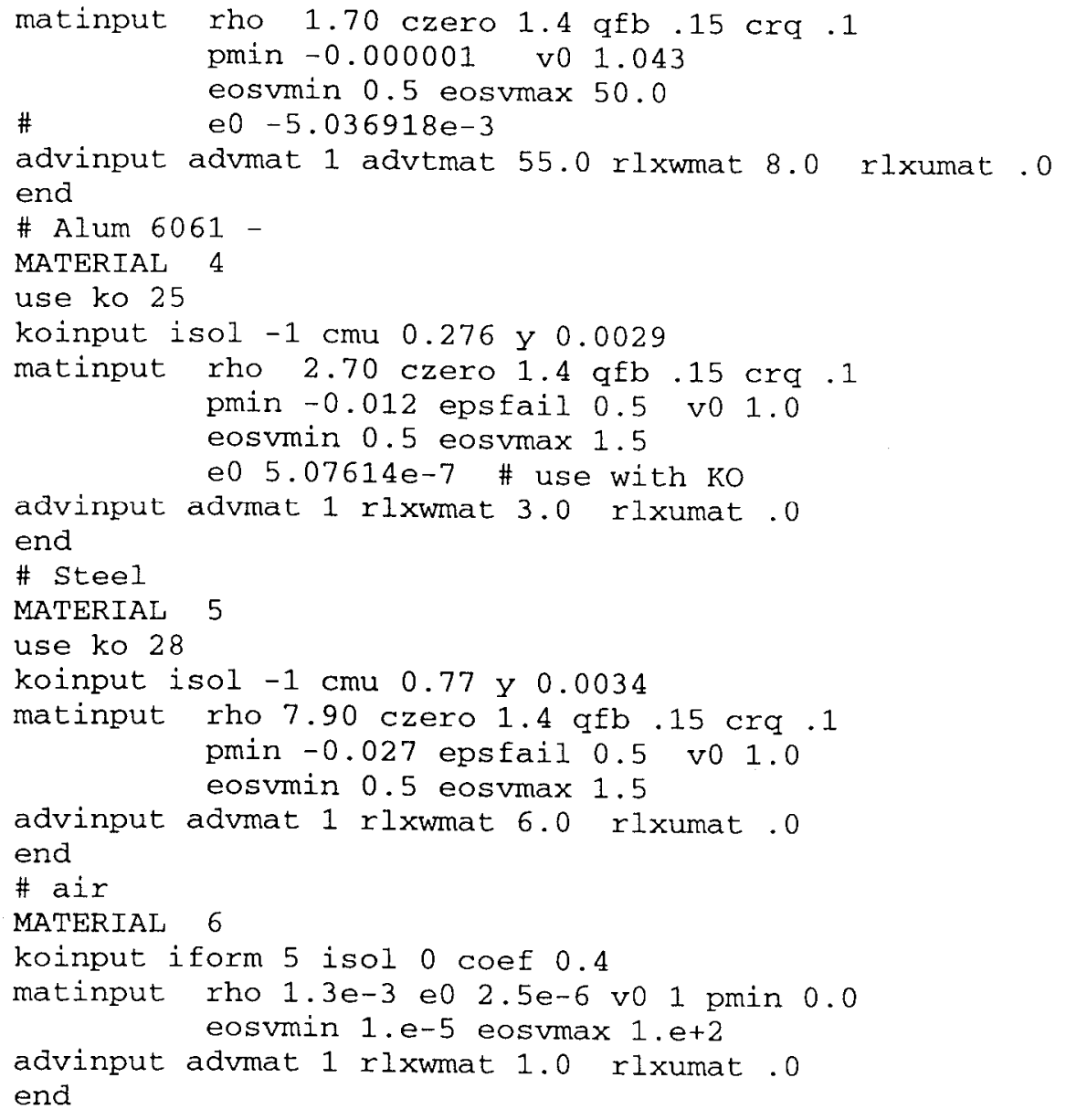




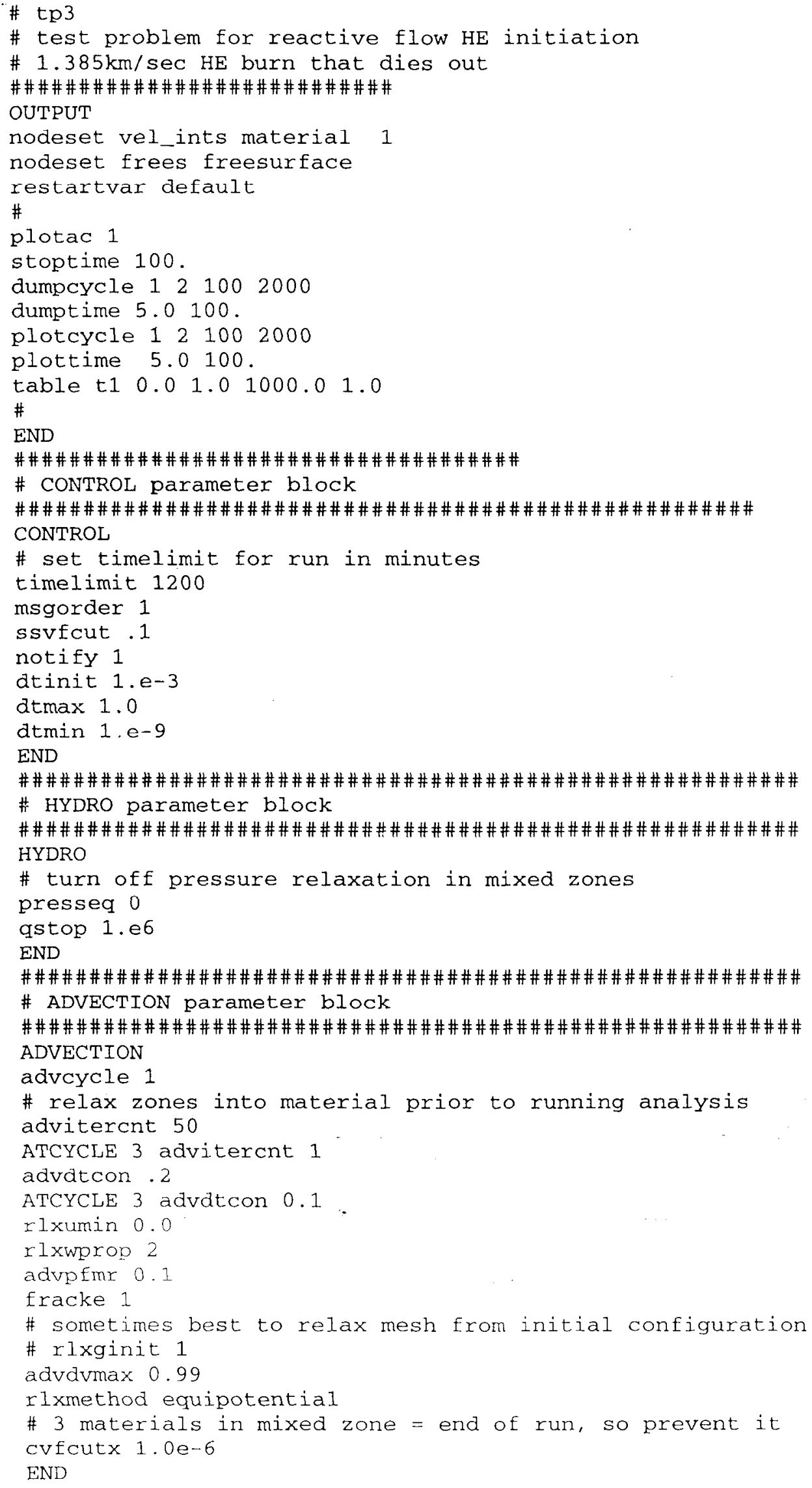




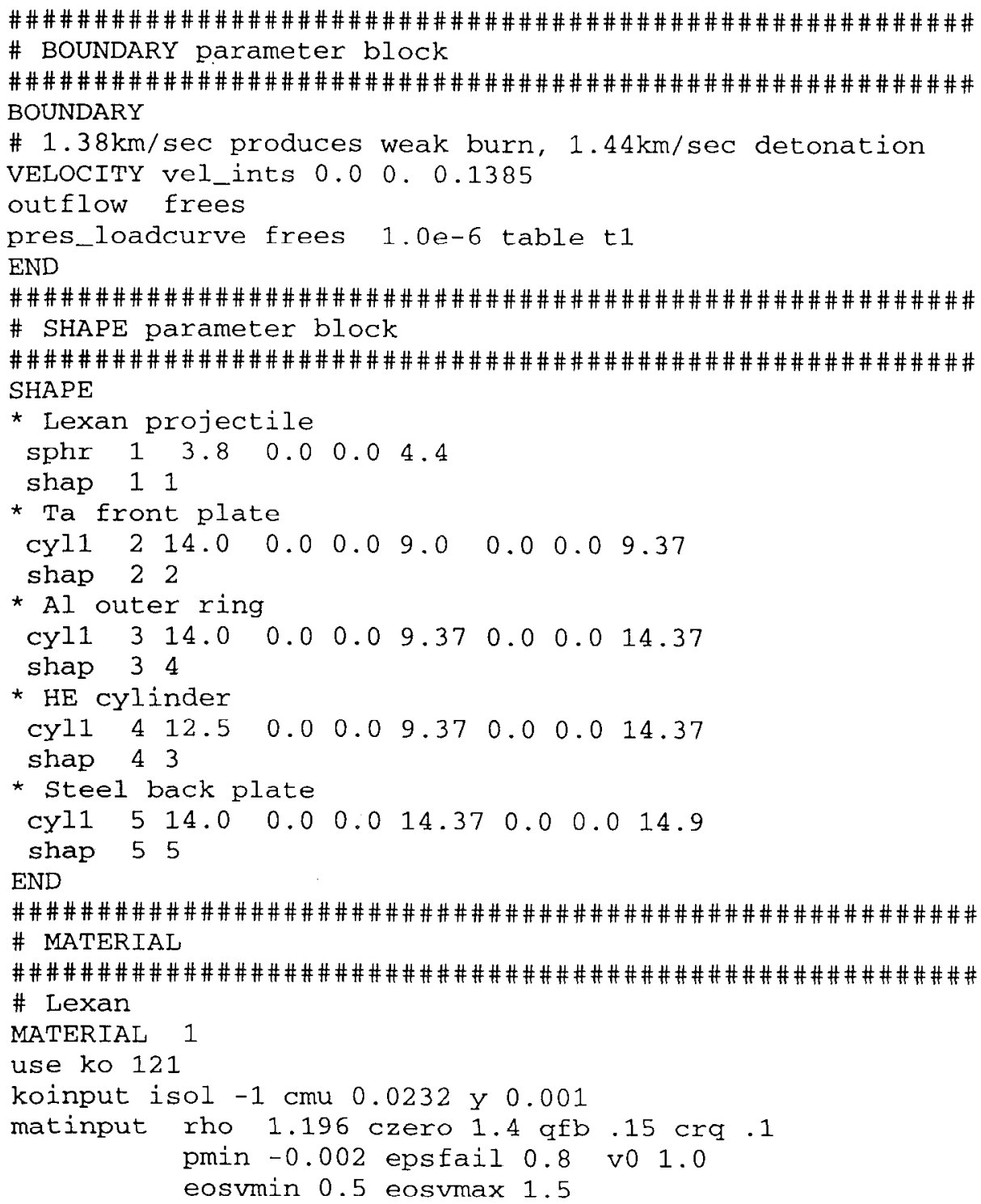




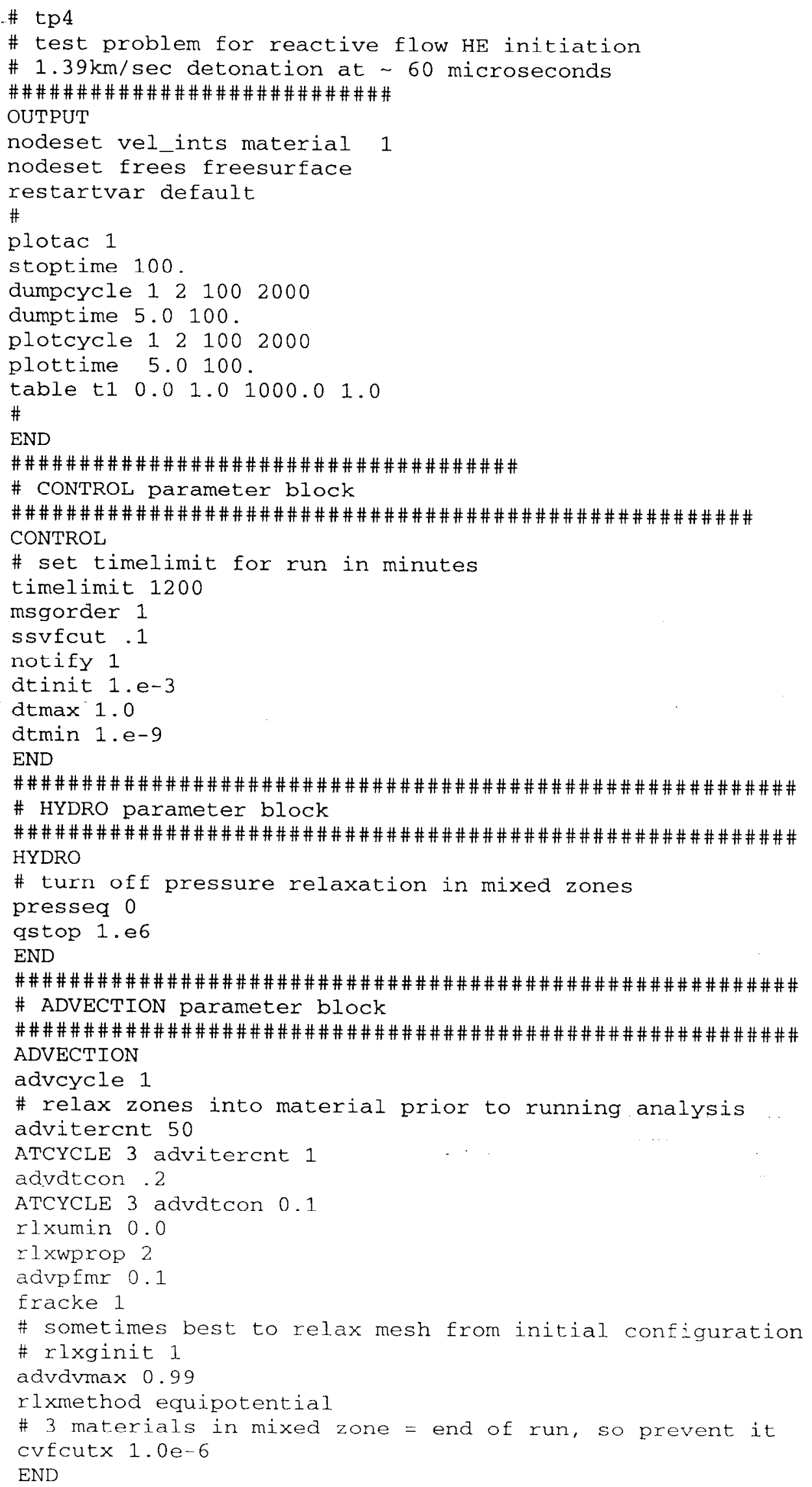




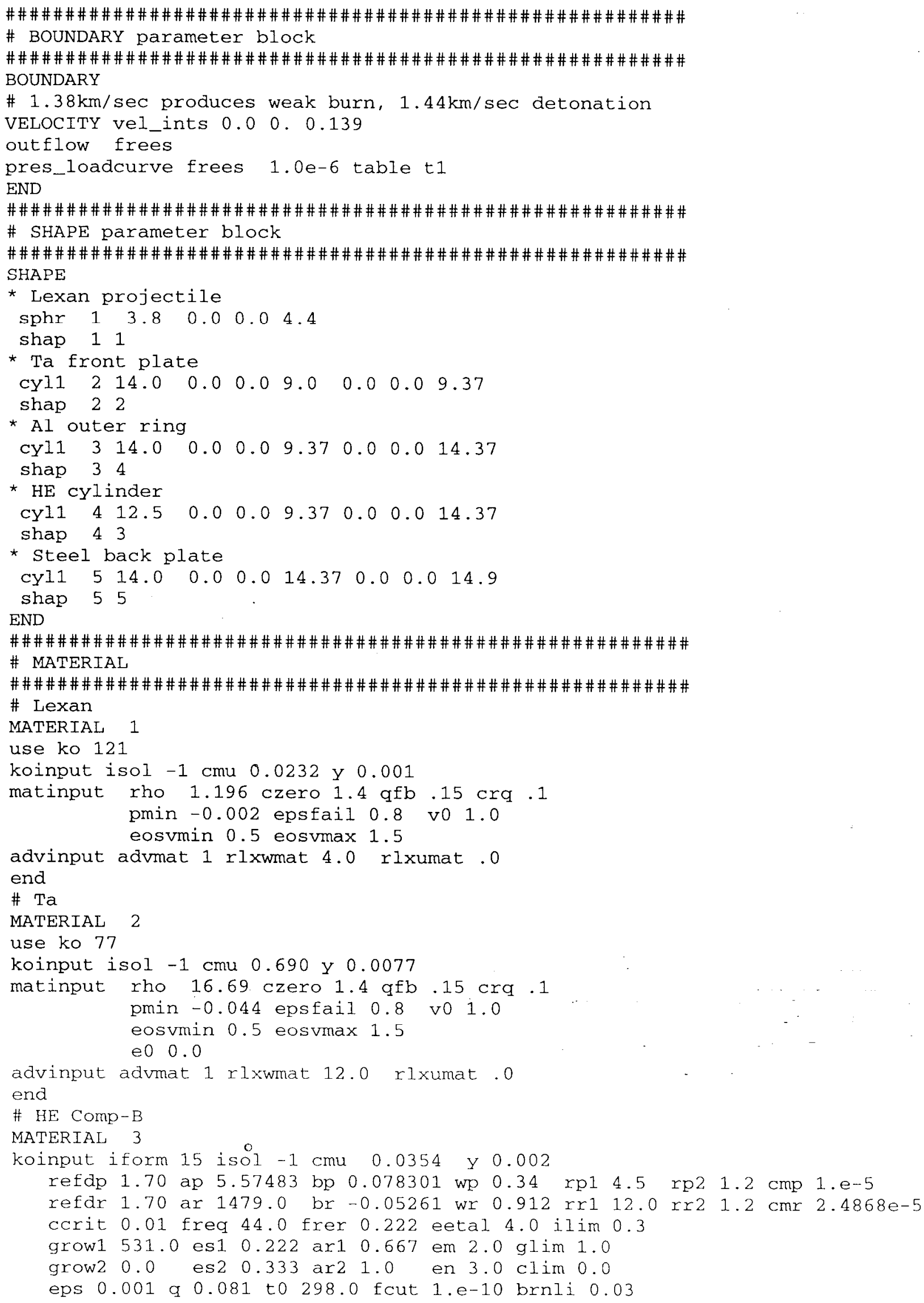


bhe 0.0

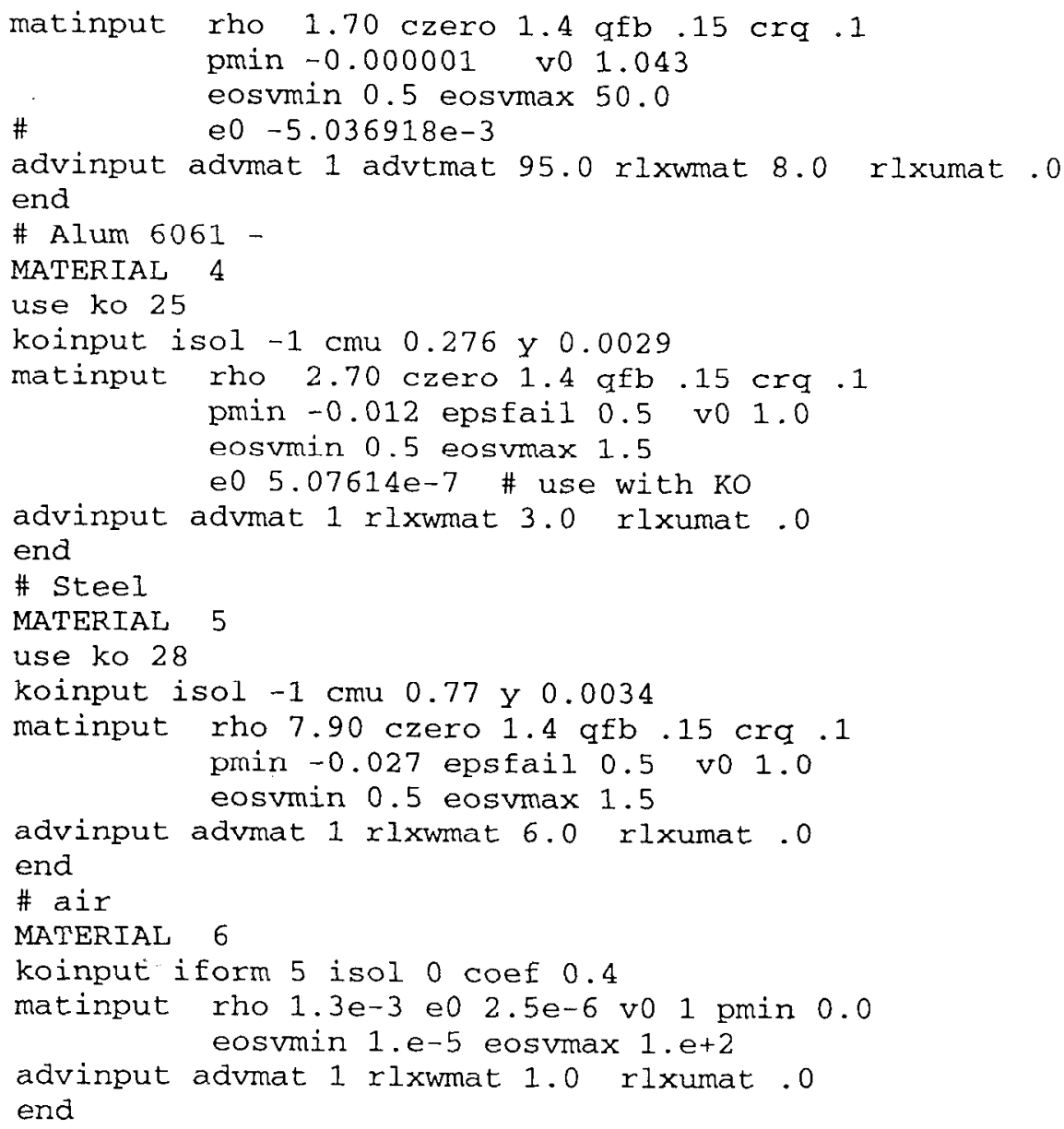


bhe 0.0

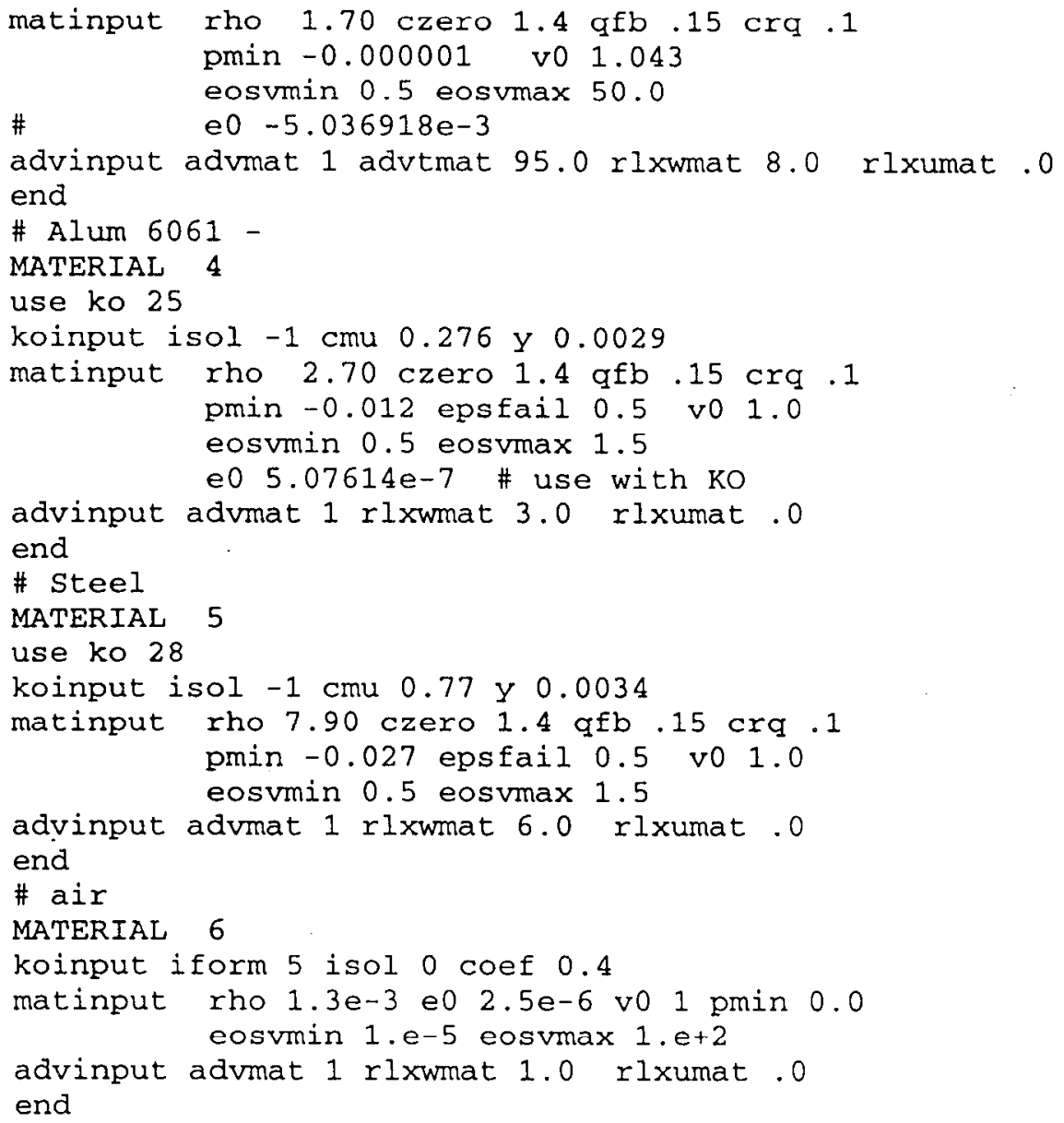

